\title{
Mudança do comportamento de valores extremos de retornos de ativos financeiros de acordo com níveis de volatilidade
}

\author{
José Alcimar Freschi
}

\author{
Dissertação apresentada \\ ao \\ Instituto de Matemática e Estatística \\ da \\ Universidade de São Paulo \\ para \\ obtenção do grau \\ de \\ Mestre em Estatística \\ Área de Concentração Estatística \\ Orientador Prof. Dr. Vladimir Belitsky
}

São Paulo - junho - 2005 


\section{RESUMO}

Para a formação de estratégias de investimentos, composição de garantias e outras operações financeiras, as instituições financeiras utilizam, entre outros indicadores, previsões de stress do mercado, o qual, também entre outros fatores, é medido pela volatilidade de ativos financeiros. É comum ser divulgado que é de alta, baixa ou até média a previsão de stress do mercado; essa graduação em níveis pode ser até mais diluída. As instituições financeiras utilizam, dependendo dessas previsões, estratégias diferentes. As estratégias que são traçadas para regimes de alta volatilidade preocupam-se em enfatizar grandes perdas ou ganhos. As formações dessas estratégias utilizam estimativas de valores extremamente grandes de investimentos e estimativas de co-integração de grandes valores de diversos fatores de investimentos. Nesse sentido, a proposta deste trabalho, é a análise de retornos de ativos financeiros segundo estimativas de volatilidade crescentes. Para tanto, procura-se, por meio de ferramentas estatísticas, desenvolver subsídios para tal fim.

Elabora-se estudo sobre estimativas de volatilidade de retornos de ativos financeiros por meio de três modelagens bastante utilizadas em séries de ativos financeiros. Obtidas as estimativas de volatilidade, adota-se faixas de volatilidade em nível crescente e obtêm-se as séries de retornos correspondentes. Por meio de análise prévia de estatísticas descritivas e da aplicação da Teoria de Valores Extremos desenvolve-se dois ensaios:

- Caso univariado - analisa-se o comportamento das caudas das respectivas distribuições com o objetivo de verificar se possuem a mesma forma, isto é, se possuem um índice caudal que as leva à mesma família de distribuições. Isso, na prática, leva a observar a relação entre que valores de retornos estão associados a determinados níveis de volatilidade.

- Caso bivariado - analisa-se a relação entre pares de ativos usando a obtenção do coeficiente implícito de dependência extremal. Isso, na prática, leva a observar se em determinados períodos em que dois ativos apresentem estimativas de volatilidade alta, os retornos correspondentes desses ativos estão mais (ou menos) correlacionados. 


\begin{abstract}
For the development of investment strategies, financial composition of collaterals and other operations, financial institutions use, in conjunction with other indicators, market stress forecasts, which are measured by the volatility of financial assets. It is of the common knowledge that market stress forecasts may be regarded as of a high, low or average level; such level scale can even be more sofisticated. Financial institutions may use, depending on those forecasts, different strategies. The strategies that are set for scenarios of high volatility are most concerned in emphasizing great losses (or profits). The development of such strategies uses an extremely large amount of investment estimates and also of a large amount of co-integration estimates of different investment factors. The proposal of this work is to analyze the financial asset returns as a function of their volatility.

We estimate the volatility of financial asset returns by three models that are widly used by financial insitutions. Once such volatility estimates are obtained, we adopt bands of volatility in increasing level and obtain the corresponding returns series. The obtained series are then studied from two points of veiw.
\end{abstract}

- Uni-variate case - we analyse the behavior of the tails of the respective distributions and verify whether they have the same shape, that is, whether their tail indexes indicate that they belong to the same distribution family.

- Bi-variate case - we analyse the relationship between pairs of assets using the implicit coefficient of extremal dependence. This analysis indicates whether in the periods when two assets present high volatility, their returns become more (or less) correlated. 


\section{Sumário}

1 Introdução $\quad 5$

2 Características dos Dados, Fontes de Informações e Programas Com$\begin{array}{lr}\text { putacionais } & 9\end{array}$

2.1 Descrição dos ativos analisädos . . . . . . . . . . . . . . . 11

2.1 .1 Taxa Pré de Juros . . . . . . . . . . . . . . . . . . . . 11

2.1 .2 Taxa Cupom Cambial . . . . . . . . . . . . . . . 11

2.1.3 Dólar Comercial . . . . . . . . . . . . . . . . . . . 12

2.1 .4 Índice Bovespa . . . . . . . . . . . . . . . . . 12

2.2 Origem dos dados . . . . . . . . . . . . . . . . . . 12

2.2 .1 Taxa Pré de Juros . . . . . . . . . . . . . . . . . . . . . 12

2.2 .2 Taxa Cupom Cambial . . . . . . . . . . . . . . 13

2.2 .3 Dólar Comercial . . . . . . . . . . . . . . . . . . . . 13

2.2 .4 Índice Bovespa . . . . . . . . . . . . . . . . . 13

2.3 Programas Computacionais . . . . . . . . . . . . . . 13

3 Séries de Retornos dos Ativos Financeiros $\quad 15$

3.1 Conceitos e Características Peculiares . . . . . . . . . . . . 15

3.2 Análise das séries de retornos dos ativos em estudo . . . . . . . . . 16

3.2 .1 Retornos do ativo Ibovespa . . . . . . . . . . . . . . 16

3.2 .2 Retornos do ativo Dólar . . . . . . . . . . . . . . . . 18

3.2 .3 Retornos do ativo Taxa Pré de Juros . . . . . . . . . . . . . . 19

3.2 .4 Retornos do ativo Taxa Cupom Cambial . . . . . . . . . . 20

4 Modelos de Estimativas de Volatilidade 21

4.1 Modelo de Volatilidade Estocástica . . . . . . . . . . . . . . . . . . . . 22

4.1 .1 Suposição teórica inicial . . . . . . . . . . . . . . 22

4.1.2 Definição do modelo de volatilidade estocástica . . . . . . . . 22

4.1 .3 Propriedades do modelo . . . . . . . . . . . . . . . . 23

4.1.4 Forma de Espaço-Estado de uma série . . . . . . . . . . . . 25

4.2 Modelo de Volatilidade - Método GARCH . . . . . . . . . . . . . 28

4.2.1 Definição do Modelo GARCH a partir da Generalização do modelo

$\mathrm{ARCH} \ldots \ldots \ldots \ldots \ldots \ldots . \ldots \ldots$

4.3 Modclo de Volatilidade - Método Média Móvel da Variabilidade da Amostra 29 
4.3.1 Definição do Modelo Média Móvel da Variabilidade da Amostra M.M.V.A . . . . . . . . . . . . . . . . 29

4.4 Análise das estimativas de volatilidade dos ativos segundo os métodos de modelagem adotados . . . . . . . . . . . . . . . . 31

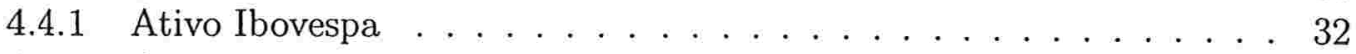

4.4 .2 Ativo Dólar . . . . . . . . . . . . . . . . . . . . . 33

4.4 .3 Ativo Taxa Pré Juros . . . . . . . . . . . . . . . . . . . . . . . . 34

4.4.4 Ativo Taxa Cupom Cambial . . . . . . . . . . . . . . . . 35

4.4.5 Análise das Estimativas de Volatilidade Obtidas . . . . . . . . . . 36

5 Ensaio $\mathrm{n}^{\circ} 1$ - Caso Univariado: Análise dos Retornos de Ativos Financeiros Correspondentes a Faixas de Estimativas de Volatilidade Crescentes $\quad$ : $\quad 37$

5.1 Teoria de Valores Extremos - TVE . . . . . . . . . . . . . . . . 37

5.1 .1 Resultado da TVE utilizado . . . . . . . . . . . . . . . . 37

5.1 .2 Método de Estimação das Caudas . . . . . . . . . . . . . . . . 39

5.2 Procedimento Experimental . . . . . . . . . . . . . . . . . . . . 40

5.2 .1 Estimação dos Parâmetros . . . . . . . . . . . . . . . . . 41

5.3 Resultados da Análise . . . . . . . . . . . . . . . . . . . . . . . 42

5.3 .1 Ativo Ibovespa . . . . . . . . . . . . . . . . . . . . . 42

5.3 .2 Ativo Dólar . . . . . . . . . . . . . . . . . . . . . 44 47

5.3 .3 Ativo Taxa Pré Juros . . . . . . . . . . . . . . . . . . . . . . . . 49

5.3 .4 Ativo Cupom Cambial . . . . . . . . . . . . . . . 51

5.4 Conclusão . . . . . . . . . . . . . . . . 53

6 Ensaio $\mathrm{n}^{\circ} 2$ - Caso bivariado: Análise da Dependência entre Pares de Retornos de Ativos Correspondentes a Faixas de Volatilidade Crescentes 56

6.1 Coeficiente Implícito de Dependência Extremal . . . . . . . . . . . . . . 56

6.2 Procedimento Experimental . . . . . . . . . . . . . . . . . 59

6.3 Resultados . . . . . . . . . . . . . . . . . . . 61

6.3.1 $1^{\circ}$ Caso - Análise da dependência de pares de ativos na mudança de faixas. . . . . . . . . . . . . . . 6 6 61

6.3.2 $2^{\circ}$ Caso - Análise da dependência extremal de pares de ativos em cada faixa. . . . . . . . . . . . . . . . . 68

6.4 Conclusão . . . . . . . . . . . . . . . . . . . . . 73 


\section{Capítulo 1}

\section{Introdução}

A partir de meados do ano de 1999, o Banco Central do Brasil iniciou estudos visando a reestruturação do Sistema de Pagamentos ${ }^{1}$ Brasileiro - SPB e, após longo período de desenvolvimento de trabalhos, conjuntamente com membros representantes de instituições do Sistema Financeiro Nacional, foi implementado (22 de abril de 2002) com uma grande reforma, onde o principal objetivo é a redução do risco sistêmico ${ }^{2}$ do mercado financeiro nacional, isto é, visa reduzir a possibilidade de ocorrência de crise no sistema financeiro.

Para a implementação do novo Sistema de Pagamentos Brasileiro foram criadas, além do Sistema de Transferência de Reservas - STR ${ }^{3}$, as Câmaras de Registro, Compensação e Liquidação ${ }^{4}$ para permitir seu funcionamento a partir da mais avançada tecnologia. Essas entidades, se forem consideradas sistemicamente importantes, têm que tomar a posição de contraparte central ${ }^{5}$ e assegurar a liquidação das operações transacionadas.

Dessa forma, a minimização de riscos sistêmicos no novo SPB depende, evidentemente, do gerenciamento eficaz dos riscos por parte das Câmaras participantes do sistema e, por isso, estão sujeitos à autorização e à supervisão do Banco Central do Brasil.

Em virtude disso, a análise da adequabilidade dos mecanismos de mitigação de riscos das câmaras de compensação e de liquidação às determinações regulamentares do Banco

\footnotetext{
${ }^{1}$ Sistema de Pagamentos Brasileiro - Um conjunto de procedimentos cuja função básica é transferir recursos, bem como processar e liquidar pagamentos para pessoas, empresas, governo, Banco Central e instituições financeiras.

${ }^{2}$ Risco Sistêmico - Risco de que a quebra de um banco provoque a quebra em cadeia de outros bancos, no chamado "efeito dominó"

${ }^{3}$ Sistema de Transferência de Reservas (STR) - Sistema operado pelo Banco Central do Brasil, em que transferências de fundos interbancárias podem ser liquidadas em tempo real, possibilitando redução dos riscos de liquidação (riscos de crédito e de liquidez) nas operações interbancárias, na medida em que a efetivação de uma transferência de fundos passou a ser condicionada à existência de saldo suficiente de recursos na conta de liquidação do participante emitente da correspondente ordem.

${ }^{4}$ Câmaras de Registro, Compensação e Liquidação - Entidades legalmente constituídas que efetuam uma série de serviços relacionados à compensação e liquidação de transações, pagamentos e gerenciamento dos riscos associados.

${ }^{5}$ Contraparte central - Diz-se de uma Câmara de Registro, Compensação e Liquidação quando esta se interpõe entre os contratantes de operações assumindo a posição oposta em cada ponta.
} 
Central é uma das importantes atribuições do Banco Central, juntamente com a implementação de mecanismos para a avaliação da volatilidade de ativos financeiros utilizados como garantias nessas câmaras bem como a análise de riscos das carteiras das instituições financeiras participantes.

Nesse sentido, o tema que norteia este trabalho refere-sc à obtenção de estimativas de volatilidade de ativos financeiros, ao estudo da relação dessas estimativas de volatilidade com os seus respectivos retornos e, em especial, à análise das correlações dos retornos de pares de ativos à medida em que suas estimativas de volatilidade se tornam crescentes.

Para tanto, optamos em focar o estudo nos ativos mais frequentemente negociados pelas instituições financeiras brasileiras, principalmente nos mercados de futuros (derivativos ${ }^{6}$ ) e, mais especificamente nos ativos financeiros denominados fatores de risco de tais contratos, os quais são integrantes do modelo de teste de stress ${ }^{7}$ adotado pela Câmara de Derivativos da Bolsa de Mercadorias e Futuros de São Paulo - BMF.

Neste trabalho, focamos o estudo nas séries de retornos desses ativos e suas respectivas estimativas de volatilidade em dois ensaios, quais sejam:

Ensaio $\mathrm{n}^{\circ}$ 1: Caso Univariado - Análise dos Retornos de Ativos Correspondentes a Faixas de Estimativas de Volatilidade Crescentes. Neste ensaio, elaboramos um estudo empírico visando analisar o comportamento das caudas das séries de retornos dos ativos, com aplicação da Teoria de Valores Extremos, à medida em que suas estimativas de volatilidade se tornam mais altas.

Ensaio $n^{\circ} 2$ : Caso Bivariado - Análise da Dependência entre Pares de Retornos de Ativos Correspondentes a Faixas de Volatilidade Crescentes. Neste ensaio, elaboramos estudo objetivando analisar a correlação entre pares de retornos de ativos, utilizando a Teoria de Valores Extremos, à medida em que suas estimativas de volatilidade, simultaneamente, se tornam mais altas e, ainda, para as séries obtidas de cada par de ativos, procuramos deduzir se para a amostra de observações simultâneas desses ativos a dependência de seus retornos aumenta ou diminui quando as situações de crise ou euforia dos mercados financeiros tornam-se mais extremas.

No desenvolvimento deste estudo, descrevemos a contextualização de tais ativos e fazemos

\footnotetext{
${ }^{6}$ Derivativos - instrumentos financeiros contratados entre duas partes para pagamentos futuros, cujos valores são derivados de outros ativos que lhes servem de referência além de seus próprios preços à vista.

${ }^{7}$ teste de stress - procedimentos utilizados na análise de cenários que visam quantificar a magnitude das perdas que podem ocorrer numa determinada carteira sob variações hipotéticas nas principais variáveis financeiras. Os testes consistem em especificar cenários, de forma subjetiva, que provocam mudanças no valor de carteiras comerciais. A utilidade dos testes de stress depende das mudanças selecionadas representarem, ou não, movimentos de mercado. Todos os ativos da carteira são reavaliados, levando-se em consideração o novo cenário. A vantagem dessa técnica consiste em avaliar situações que não estão presentes nos dados históricos, forçando os gerentes a considerar eventos que de outra forma seriam ignorados. De forma geral, os testes de stress são considerados de forma complementar às outras técnicas de mensuração de valores de risco.
} 
uma análise preliminar de suas respectivas séries de retornos, discorremos sobre modelos de estimativas de volatilidade, em especial sobre o de Volatilidade Estocástica, Modelagem GARCH e Modelagem pela Média Móvel da Variabilidade Amostral, que foram adotados nesta pesquisa para obtenção das estimativas de volatilidade dos ativos em questão, juntamente com comparação e verificação da adequabilidade de cada método, apresentamos resultados da Teoria de Valores Extremos necessários ao desenvolvimento do trabalho, expomos o Método de estimação do índice caudal das funções de distribuição dos retornos dos ativos, conhecido como Método dos Excedentes Além de um Limiar (POT - Peaks over a threshold), fazemos a análise da dependência entre os ativos estudados, utilizando o coeficiente implícito de dependência extremal sugerido e descrito no trabalho de Adonírio Panzieri, Vladimir Belitsky, Paulo R. M. Rocha e Fernando P. A. Prado (2004), com a adaptação para o cálculo de dependência desses ativos de acordo com a volatilidade crescente dos pares e procedemos à análise dos resultados para os casos univariados e bivariados.

Assim, o trabalho está organizado em 6 capítulos (incluindo esta Introdução), além de referências bibliográficas, cuja estrutura é a seguinte:

Capítulo 2: apresentamos os ativos analisados destacando em que mercados financeiros estão presentes, a relação com os principais contratos negociados por instituições financeiras no âmbito da Câmara de Derivativos da BMF no que se refere às decomposições dos contratos em seus fatores de riscos; informamos a origem das séries de dados e os programas computacionais utilizados.

Capítulo 3: fazemos uma breve exposição sobre conceitos e características de séries de retornos de ativos financeiros, apresentamos a análise gráfica e estatística dessas séries e analisamos as características observadas para as séries de retornos de cada um dos ativos.

Capítulo 4: discorremos sobre modelos de estimativas de volatilidade com enfoque no de Volatilidade Estocástica, Modelagem GARCH e no de Modelagem pela Média Móvel da Variabilidade Histórica amostral dos retornos e, ainda, apresentamos os resultados das estimativas obtidas juntamente com as análises sobre os modelos ajustados para cada uma das séries de retornos de ativos do estudo.

Capítulo 5: exibimos o Ensaio $\mathrm{n}^{\circ}$ 1, iniciando por discorrer sobre o procedimento para determinação das séries de retornos dos ativos correspondentes à níveis (pré-determinados) de suas respectivas estimativas de volatilidade, descrevemos os conceitos e resultados da Teoria de Valores Extremos usados neste trabalho, apresentamos o método de estimação do índice caudal (POT) das distribuições das séries dos retornos dos ativos e expomos os resultados desse ensaio por meio de gráficos, testes de normalidades correspondentes às séries obtidas conforme relatado no início deste item e analisamos o comportamento do índice caudal dessas séries.

Capítulo 6: exibimos o Ensaio $\mathrm{n}^{\mathrm{o}}$ 2, onde descrevemos o procedimento para determinação das séries bivariadas de retornos dos ativos correspondentes à níveis (pré-determinados) 
de suas respectivas estimativas de volatilidade, apresentamos o método de obtenção do coeficiente de dependência de extremos e expomos os resultados deste ensaio relativamente ao obtido na análise pelas correlações lineares e pelo comportamento do coeficiente de dependência extremal das séries bivariadas obtidas conforme dito no início deste item. 


\section{Capítulo 2}

\section{Características dos Dados, Fontes de Informações e Programas Computacionais}

Em função de que os ativos em análise neste trabalho serem específicos de um setor do mercado financeiro (derivativos), para melhor abordagem dos mesmos faz-se necessário alguns esclarecimentos iniciais quanto às suas definições, segmentos em que estão presentes assim como também em que tipos de contratos são utilizados. Os derivativos englobam uma série de segmentos do mercado financeiro com critérios e formação de preços específicos. Esses segmentos (Veja ...) são classificados em:

A - Mercados a Termo

Composto por contratos de compra e venda de uma quantidade determinada de ativos de mercado por um preço previamente estabelecido para serem liquidados em certa data futura. É normalmente negociado em mercado de balcão e não é padronizado, sendo que ao final do contrato o negócio deve ser efetivado e, normalmente, feito por meio de liquidação financeira. Nessa modalidade os principais contratos que são transacionados são os contratos a termo de DI (Depósitos Interfinanceiros) e contratos a termo de Ouro.

B - Mercados de Futuros

Composto por contratos de compra e venda de uma quantidade determinada de ativos de mercado por um preço previamente estabelecido para serem liquidados em certa data futura, porém com alto grau de padronização, onde só o preço é definido entre as partes envolvidas no negócio. A BMF, por meio de sua câmara de compensação de derivativos funciona como contraparte central das operações, isto é, garantia de que as operações sejam liquidadas. Assim, o contrato futuro, por ter maior facilidade de transação, apresenta maior liquidez (Bessada, 1994). Nessa modalidade os principais contratos que são transacionados são os de Dólar Futuro, DI Futuro, Futuro Ibovespa, Futuro Ouro e Futuro de Taxa de Câmbio de Reais por Dólar ou Euro.

C - Mercados de Swaps

Composto de contratos entre duas partes que visam troca de fluxos de caixa futuros por 
um determinado período de tempo, com metodologia de cálculos definidas previamente. Não possuem alto grau de padronização, são negociados no mercado de balcão e, normalmente registrados na BMF, sendo que em alguns casos o registro se dá no BACEN (Banco Central do Brasil). Nessa modalidade os principais contratos que são transacionados são os de swaps de taxa de juros, swaps de moedas e swaps de moedas e taxas de juros.

\section{D - Mercados de Op̧̧ões}

Composto de contratos que representam um direito de compra (ou de venda) de ativos de mercado com preço previamente estabelecido com validade por período determinado. As opções são negociadas em Casas de Bolsas de Valores. Algumas opções não têm alto grau de padronização, sendo negociadas no Mercado de Balcão podendo ter registro na BMF. Nessa modalidade os principais contratos que são transacionados são os de Opções com DI, Opções com Dólar, Opções com Ibovespa e Opções com Ouro.

Neste trabalho consideramos alguns dos contratos dos segmentos acima descritos, os quais, de acordo com a BMF (Resenha BMF - $\mathrm{n}^{\circ} 139$ ) são os principais ativos negociados por instituições financeiras brasileiras, a seguir relacionados: Futuros a Termo de Ações , Opções de Ações, Futuros de Dólar, Opções de Dólar e Papéis Cambiais. Nesses contratos os principais ativos, que são objetos de negociação são o Índice de ações da Bolsa de Valores de São Paulo (Índice Bovespa-Ibovespa), taxa de câmbio de reais por dólar dos Estados Unidos e as taxas pré de juros e cupom cambial

A BMF, no artigo técnico citado acima, descreve o modelo de teste de stress, utilizado pela Câmara de derivativos e que compõe o seu subsistema de margem de garantias exigido das instituições que operam naquela Câmara, para as transações financeiras em que executa o papel de contraparte central. Para a formulação desse modelo, uma das etapas básicas é a decomposição de todos os ativos de determinados contratos em fatores de risco, também chamados de fatores primitivos, ou seja, o conjunto dos ativos que comporão os valores dos derivativos - preços dos ativos-objetos finais. A Tabela 2.1 apresenta a relação dos principais contratos que consideramos neste trabalho com os seus respectivos fatores de risco:

Tabela 2.1: Principais Contratos e suas decomposições em Fatores de Risco

\begin{tabular}{|c|c|c|c|c|}
\hline \multirow{2}{*}{ Contratos } & \multicolumn{4}{|c|}{ Fatores de risco } \\
\cline { 2 - 5 } & Tx pre de juros & Tx cupom cambial & Dólar & Ibovespa \\
\hline \hline Futuros de Dólar & $*$ & $*$ & $*$ & \\
\hline Opções de Dólar & $*$ & $*$ & $*$ & $*$ \\
\hline Papéis cambiais & & $*$ & $*$ & \\
\hline Opções de Ações & $*$ & & & $*$ \\
\hline Fut.Termo Ações & $*$ & & & $*$ \\
\hline
\end{tabular}

Neste trabalho estudamos a volatilidade nas séries de retornos de cada um dos fatores de risco relacionados na Tabela 2.1 - Taxa Pré de Juros, Taxa Cupom Cambial, 
Dólar e o índice Bovespa (Ibovespa) - e, em um dos ensaios deste trabalho, verificamos a dependência entre os retornos dos fatores que compõem cada contrato nos períodos em que as suas estimativas de volatilidade tendam aos extremos, isto é, à medida em que dois ativos (fatores de risco de determinado contrato) passem a ter suas estimativas de volatilidade mais altas, analisamos como isso se reflete nos seus retornos, correspondentes a esses períodos, relativamente ao aspecto de que sejam mais ou monos correlacionados. Ressaltamos que tal procedimento empírico, aqui desenvolvido, não visa contestar/atestar a adeqüabilidade do modelo de teste de stress utilizado pela Câmara de derivativos da BMF citado anteriormente mas, tão somente, registrarmos os resultados de dependência dos retornos em períodos de estimativas de volatilidade crescente entre ativos, com o uso de ferramentas/programas estatísticos que apresentaremos mais adiante, para conclusões acadêmicas/financeiras, podendo servir de subsídio para futuros estudos visando a análise de riscos de carteiras.

\subsection{Descrição dos ativos analisados}

Nesta Secção descrevemos a definição e a forma como são compostos e obtidos os ativos estudados neste trabalho, quais sejam:Taxa Pré de Juros, Taxa Cupom Cambial, Dólar e o índice Bovespa (Ibovespa)

\subsubsection{Taxa Pré de Juros}

Taxa prefixada em relação a outra variável negociada no contrato, expressa em percentual ao ano, com até seis casas decimais. São taxas associadas a prazos fixos previamente escolhidos também qualificados como vértices da estrutura a termo. Os vértices em vigor para efeito de construção da estrutura a termo das taxas de juros prefixadas são os prazos de $1,21,42,63,126,252,504$ e 756 dias úteis.

A cada dia útil, são calculadas as taxas a serem incorridas para os diferentes prazos escolhidos, que propiciam a geração de séries diárias para cada um dos vértices.

São utilizados dados relativos ao CDI, a contratos de futuros e de swaps negociados na $\mathrm{BMF}$ e que representam os instrumentos mais líquidos.

\subsubsection{Taxa Cupom Cambial}

Taxa de juro, denominada de cupom cambial, expressa em percentual ao ano, com duas casas decimais, representativa da diferença entre as taxas de juro efetiva e a variação cambial definidas, para esse efeito, como:

a - a taxa de juro efetiva de Depósitos Interfinanceiros - DI, calculada a partir da acumulação das taxas médias diárias de DI de um dia, apuradas pela Central de Custódia e de Liquidação Financeira de Títulos - Cetip, para o período compreendido entre a data da operação no mercado futuro, inclusive, e o último dia do mês anterior ao mês de vencimento do contrato, inclusive. 
b - a variação cambial, medida pela taxa de câmbio de reais por dólar dos Estados Unidos, para entrega pronta, contratada nos termos da Resolução 1690/90, do Conselho Monetário Nacional - CMN, apurada e divulgada pelo Banco Central do Brasil e observada entre o dia útil anterior à data da operação no mercado futuro, inclusive, e o último dia do mês anterior ao mês de vencimento do contrato, inclusive.

\subsubsection{Dólar Comercial}

Taxa de câmbio em reais por dólar dos Estados Unidos, ou seja, é o valor em reais do dólar americano utilizado nas operações comerciais do país, no pagamento de dívida externa e nas remessas de dividendos das empresas com sede no exterior.

\subsection{4 Índice Bovespa}

Indicador do desempenho médio das cotações do mercado brasileiro de ações, retratando o comportamento dos principais papéis negociados na Bolsa de Valores de São Paulo. É definido como o valor atual da aplicação de uma carteira teórica de ações. O número de ações que compõe essa carteira teórica procura aproximar-se do máximo possível da real configuração das negociações. Para tanto, para que uma ação seja integrante da carteira que compõe o índice Bovespa é necessário que ela tenha representatividade no mercado à vista em termos de números de negócios e volume em moeda corrente - ajustado ao tamanho da amostra. Assim, dá maior peso a ações de maior liquidez. A apuração do Índice Bovespa é o somatório dos pesos (quantidade teórica da ação multiplicada pelo último preço da mesma) das ações integrantes de sua carteira teórica. Assim sendo, pode ser apurado, a qualquer momento, por meio da seguinte fórmula:

Ibovespa $_{t}=\sum_{i=1}^{n} P_{i t} * Q_{i t}$ onde:

Ibovespa $_{t} \rightarrow$ Índice Bovespa no instante $t$.

$n \rightarrow$ número total de ações componentes da carteira teórica.

$P_{i t} \rightarrow$ último preço da ação $i$ no instante $t$.

$Q_{i t} \rightarrow$ quantidade teórica da ação $i$ no instante $t$.

\subsection{Origem dos dados}

\subsubsection{Taxa Pré de Juros}

A série de valores da Taxa Pre de Juros foi fornecida pela BMF (Área de Risco) também disponibilizada na página da Internet no item Serviços - Sistema de Recuperação de Informações. As taxas diárias são correspondentes à estrutura de vértice 252 dias úteis no período de 10/12/1997 e 20/04/2004. Foram utilizados todos dados da amostra (sem 
expurgar os índices inflacionários do período e sem excluir nem acrescentar valores).

\subsubsection{Taxa Cupom Cambial}

A série de valores da Taxa Cupom Cambial foi fornecida pela BMF (Área de Risco) também disponibilizada na página da Internet no item Serviços - Sistema de Recuperação de Informações. As taxas diárias são correspondentes à estrutura de vértice 252 dias úteis no período de 10/12/1997 e 20/04/2004. Foram usados os dados reais (sem retirar e nem acrescentar valores).

\subsubsection{Dólar Comercial}

A série Dólar Comercial foi obtida da base de dados do Banco Central do Brasil disponibilizada na página da Internet no item Economia e Finanças. As cotações diárias (expressas em unidade monetária corrente - Reais pelo valor de 1 dólar) correspondem aos valores de fechamento entre 10/12/1997 e 20/04/2004. Foram utilizados todos dados da amostra (sem expurgar os índices inflacionários do período e sem excluir nem acrescentar valores).

\subsection{4 Índice Bovespa}

A série do índice Bovespa foi obtida da base de dados do Banco Central do Brasil disponibilizada na página da Internet no item Economia e Finanças. As cotações diárias (em pontos) correspondem aos valores de fechamento entre 10/12/1997 e 20/04/2004. Foram usados os dados reais (sem expurgar os índices inflacionários do período e sem excluir nem acrescentar valores).

\subsection{Programas Computacionais}

Como base intermediária de preparação dos dados utilizamos:

Excel, Word e Bloco de Notas.

Para o cálculo das estimativas de volatilidade das séries de retornos dos ativos:

Give Win - Stamp, Eviews e Excel.

Para a elaboração de programas:

Matlab e Stat Pascal.

Para o cálculo e análise do coeficiente de dependência extremal dos retornos e rodar programa em Stat Pascal:

Xtremes 3.0. 
Para construção de gráficos para análises conclusivas: SPSS.

Para redação do trabalho:

Latex 


\section{Capítulo 3}

\section{Séries de Retornos dos Ativos Financeiros}

\subsection{Conceitos e Características Peculiares}

Os ativos financeiros têm seus valores expressos de acordo com as suas próprias definições e características e, no desenvolvimento deste trabalho, optamos pela análise das séries dos retornos de ativos financeiros, que são livres de unidades de medidas possibilitando comparações com os retornos de outros ativos financeiros.

Sejam:

$\operatorname{Pr}_{t} \rightarrow$ valor de um ativo no instante $t$.

$\operatorname{Pr}_{t-1} \rightarrow$ valor de um ativo no instante $t-1$.

$r_{t} \rightarrow$ série de retornos de um ativo no instante $t$, definida como:

$r_{t}=\ln \left(\frac{P r_{t}}{P r_{t-1}}\right)=\ln \left(P r_{t}\right)-\ln \left(P r_{t-1}\right)$, como sendo o retorno contínuo.

$r_{t}=\frac{P r_{t}-P r_{t-1}}{P r_{t-1}}$, como sendo o retorno discreto (simples).

Os retornos contínuos apresentam vantagens em relação aos discretos visto que para pequenas variações nos preços dos ativos, são aproximadamente iguais e, ainda, o retorno contínuo em determinado período pode ser obtido pela simples soma dos retornos de cada um dos instantes.

Neste trabalho usamos os retornos contínuos das séries e, ainda, para possibilitar que a série de retornos tenha média zero, de acordo com sugestão apresentada por Kim et al. 1998 (Veja ...), os retornos das séries foram corrigidos $\left(r_{t}^{c}\right)$ e obtidos por meio da expressão:

$r_{t}^{c}=100 *\left[\left(\ln \left(P r_{t}\right)-\ln \left(P r_{t-1}\right)\right)-\frac{1}{n} * \sum_{t=1}^{n}\left(\ln \left(P r_{t}\right)-\ln \left(P r_{t-1}\right)\right)\right]$, onde $n$ é a quantidade de observações.

Em geral, é muito difícil obter a distribuição das séries de retornos financeiras e para análise de suas características faz-se uso de seus momentos de determinadas ordens como a média, variância e função de autocovariância e testa-se condições de estacionariedade e normalidade. 
Os primeiros modelos teóricos para retornos de séries financeiras pressupunham que os mesmos seguiam processos Gaussianos mas, pesquisas nessa área - iniciando com o artigo de Mandlebrot (1963), onde ele constatou características como mudança de variância com o tempo, caudas pesadas e altos (baixos) retornos geralmente seguidos por altos (baixos) para as distribuições não condicionais das séries de retornos financeiras -, fizeram com que vários pesquisadores constatassem alguns fatos peculiares às essas sćries em questão, tais como:

- Suas distribuições apresentam caudas pesadas, comparativamente a uma distribuição normal. Isso significa que movimentos bruscos nos preços ocorrem com maior freqüência do que aquela implícita em séries com uma distribuição normal.

- Suas distribuições costumam ter a forma das curvas afiladas, comparativamente à uma distribuição normal, isto é, o pico da curva de distribuição de probabilidades dos retornos é maior e mais estreito que aquele da distribuição normal. Essa característica em conjunto com a anterior caracteriza uma distribuição leptocúrtica.

- Apresentam maior risco (volatilidade) quando são negativos.

- Apresentam conglomerados de variabilidade, isto é, período de alta (baixa) volatilidade é seguido por período também de alta (baixa).

- Geralmente não autocorrelacionados ou com baixo grau de autocorrelação embora a série dos quadrados dos retornos freqüentemente tenha significativa autocorrelação.

- Geralmente apresentam volatilidade próxima nos instantes $t$ e $t-1$, sendo esse fato denominado de memória longa.

- Mudança da variância com o tempo, isto é, são heterocedásticos.

- Algumas são não-lineares, isto é, de uma maneira geral, a variabilidade não se manifesta da mesma maneira no tocante a choques positivos ou negativos.

\subsection{Análise das séries de retornos dos ativos em es- tudo}

Apresentamos neste item análise gráfica e estatística descritiva das séries de retornos dos ativos Dólar Comercial, Índice Bovespa, Taxa Pré de Juros e Taxa Cupom Cambial no período de 12/12/1997 a 20/04/2004, totalizando 1594 observações. Destacamos que, durante o período em questão, ocorreram fatos atípicos no mercado financeiro influenciados pela crise da Rússia (agosto de 1998), desvalorizações do Real (janeiro de 1999 e setembro de 2002) e queda da bolsa NASDAQ - Nacional Association of Securities Dealears Quotation System - índice de mercado acionário norte-americano (abril de 2000).

\subsubsection{Retornos do ativo Ibovespa}

Apresentamos para análise exploratória a Tabela 3.1 e as Figuras 3.1 e 3.2

Características observadas: 


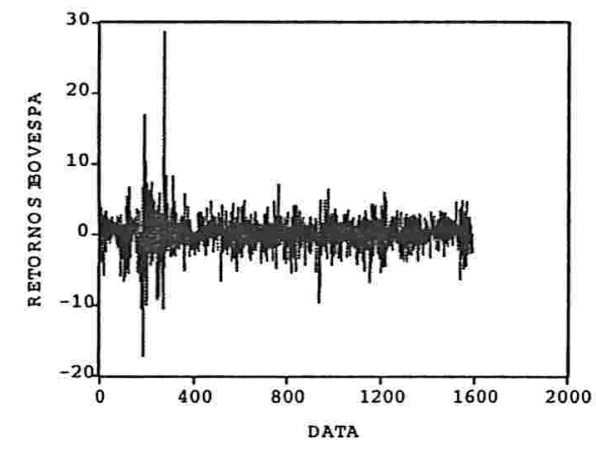

Figura 3.1: Gráfico dos retornos diários da série Ibovespa

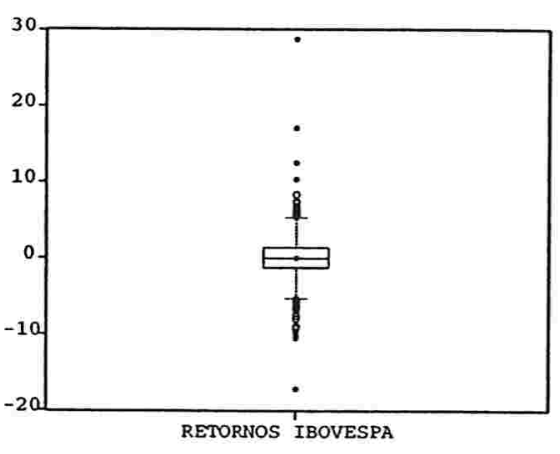

Figura 3.2: Box-plot dos retornos da série Ibovespa

Tabela 3.1: Estatística Descritiva da série de retornos do Ibovespa

\begin{tabular}{|l|c|}
\hline \multicolumn{2}{|l|}{ Estatística Descritiva } \\
\hline \hline Número de observações & 1594 \\
\hline Mínimo & -17.27 \\
\hline Mediana & -0.025 \\
\hline Média & 0.00 \\
\hline Máximo & 28.76 \\
\hline D.padrão & 2.46 \\
\hline Assimetria & 0.84 \\
\hline Curtose & 15.57 \\
\hline \hline Teste de Jarque-Bera & 16185 \\
Probabilidade & 0.00 \\
\hline \hline
\end{tabular}

- os retornos oscilam em torno do zero (média) indicando a sua estacionariedade na média. - a existência de assimetria e o excesso de curtose, juntamente com o teste de Jarque-Bera são, a princípio, fatores indicativos de não normalidade.

- as observações mais extremas da cauda direita correspondem às datas de 15/01/1999, 15/09/1998, 11/09/1998 e 23/09/1998 e são efeitos da pós crise da Rússia (agosto de 1998) e a desvalorização do Real (janeiro de 1999) enquanto que a observação mais destacada da cauda esquerda corresponde à data de 10/09/1998 e é efeito da crise da Rússia (agosto de 1998) 


\subsubsection{Retornos do ativo Dólar}

Apresentamos para análise exploratória a Tabela 3.2 e as Figuras 3.3 e 3.4

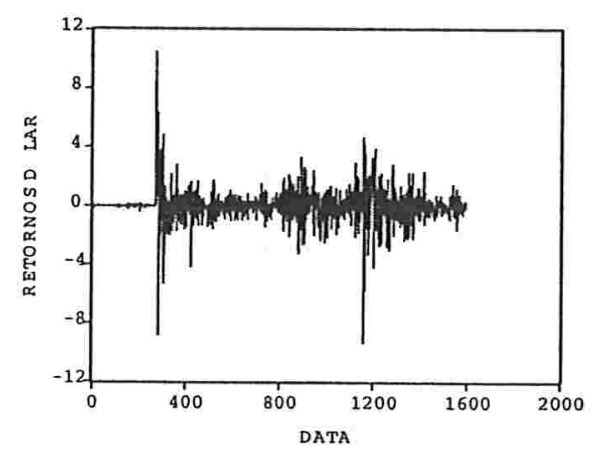

Figura 3.3: Gráfico dos retornos diários da série Dólar

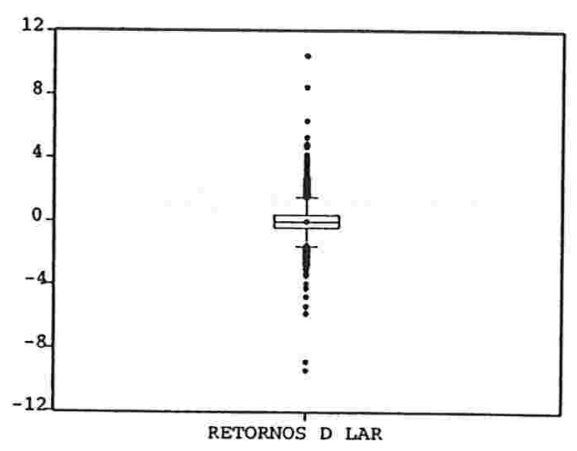

Figura 3.4: Box-plot dos retornos da série Dólar

Tabela 3.2: Estatística Descritiva da série de retornos do Dólar

\begin{tabular}{|l|c|}
\hline \multicolumn{2}{|l|}{ Estatística Descritiva } \\
\hline \hline$N^{\circ}$ Observações & 1594 \\
\hline Mínimo & -9.41 \\
\hline Mediana & -0.02 \\
\hline Média & 0.00 \\
\hline Máximo & 10.46 \\
\hline D.padrão & 1.06 \\
\hline Assimetria & 0.33 \\
\hline Curtose & 21.30 \\
\hline \hline Jarque-Bera & 22288 \\
Probabilidade & 0 \\
\hline \hline
\end{tabular}

Características observadas:

- os retornos oscilam em torno do zero (média) indicando a sua estacionariedade na média. - a existência de assimetria e o excesso de curtose, juntamente com o teste de Jarque-Bera são, a princípio, fatores indicativos de não normalidade.

- as observações mais extremas da cauda direita correspondem às datas de 13/01/1999, 15/01/1999 e 26/01/1999 e são efeitos da desvalorização do Real (janeiro de 1999) enquanto que as observações mais destacadas da cauda esquerda correspondem às datas de 02/02/1999 (efeito da pós crise Real) e 02/08/2002. 


\subsubsection{Retornos do ativo Taxa Pré de Juros}

Apresentamos para análise exploratória a Tabela 3.3 e as Figuras 3.5 e 3.6

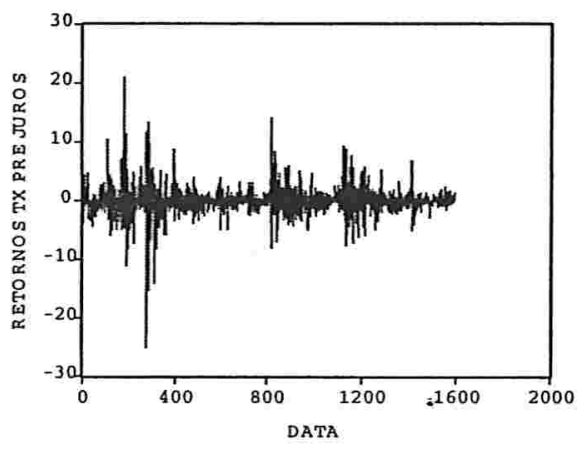

Figura 3.5: Gráfico dos retornos diários da série Taxa Pré de Juros

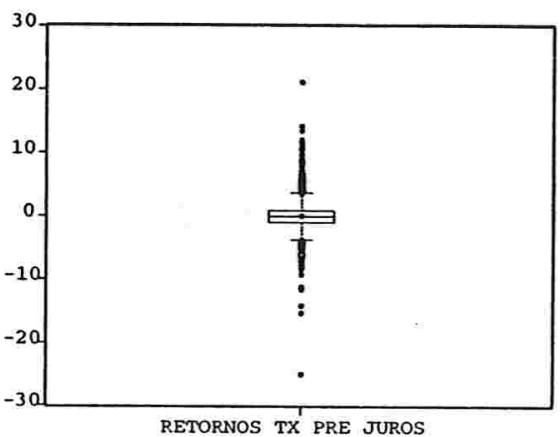

Figura 3.6: Box-plot dos retornos da série Taxa Pré de Juros

Tabela 3.3: Estatística Descritiva da série de retornos da Taxa Pré de Juros

\begin{tabular}{|l|c|}
\hline \multicolumn{2}{|l|}{ Estatística Descritiva } \\
\hline \hline $\mathrm{N}^{\circ}$ Observações & 1594 \\
\hline Mínimo & -25.10 \\
\hline Mediana & -0.05 \\
\hline Média & 0.00 \\
\hline Máximo & 21.14 \\
\hline D.padrão & 2.45 \\
\hline Assimetria & 0.05 \\
\hline Curtose & 18.81 \\
\hline \hline Jarque-Bera & 16113 \\
Probabilidade & 0 \\
\hline \hline
\end{tabular}

Características observadas:

- os retornos oscilam em torno do zero (média) indicando a sua estacionariedade na média. - a existência de assimetria e o excesso de curtose, juntamente com o teste de Jarque-Bera são, a princípio, fatores indicativos de não normalidade.

- as observações mais extremas da cauda direita correspondem às datas de 27/08/1998, 21/01/1999, 27/01/1999 e são efeitos da desvalorização do Real (janeiro de 1999) enquanto que as observações mais destacadas da cauda esquerda correspondem às datas de 14/09/1998, 15/01/1999, 01/02/1999 e 09/03/1999 e são efeitos da crise da Rússia (agosto de 1998) e a desvalorização do Real (janeiro de 1999). 


\subsubsection{Retornos do ativo Taxa Cupom Cambial}

Apresentamos para análise exploratória a Tabela 3.4 e as Figuras 3.5 e 3.6

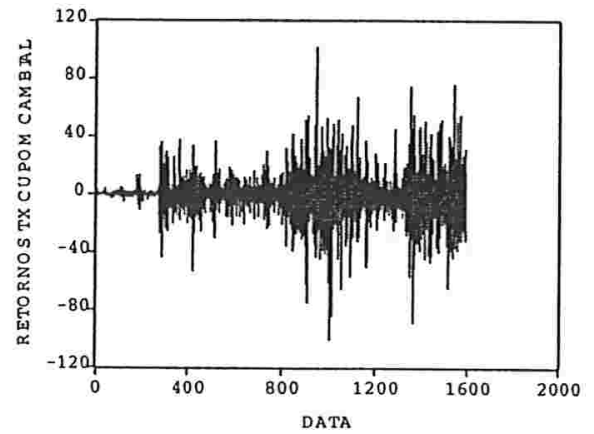

Figura 3.7: Gráfico dos retornos diários da série Taxa Cupom Cambial

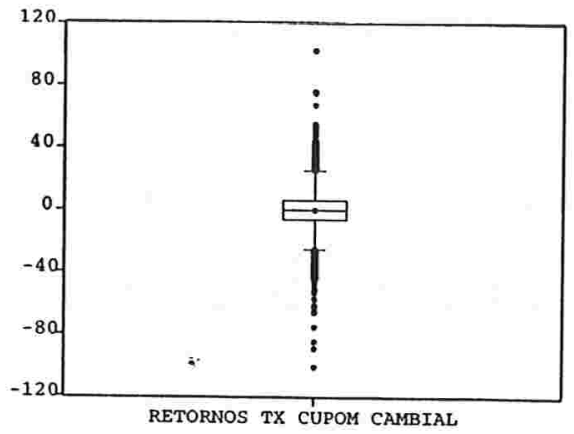

Figura 3.8: Box-plot dos retornos da série Taxa Cupom Cambial

Tabela 3.4: Estatística Descritiva da série de retornos da Taxa Cupom Cambial

\begin{tabular}{|l|c|}
\hline \multicolumn{2}{|l|}{ Estatística Descritiva } \\
\hline \hline $\mathrm{N}^{\circ}$ Observações & 1594 \\
\hline Mínimo & -101.15 \\
\hline Mediana & 0.06 \\
\hline Média & 0.00 \\
\hline Máximo & 102.47 \\
\hline D.padrão & 16.69 \\
\hline Assimetria & -0.07 \\
\hline Curtose & 7.67 \\
\hline \hline Jarque-Bera & 1452 \\
Probabilidade & 0 \\
\hline \hline
\end{tabular}

Características observadas:

- os retornos oscilam em torno do zero (média) indicando a sua estacionariedade na média. - a existência de assimetria e o excesso de curtose, juntamente com o teste de Jarque-Bera são, a princípio, fatores indicativos de não normalidade.

- as observações mais extremas da cauda direita correspondem às datas de 24/09/2001, $13 / 06 / 2002$, 06/05/2003 e 30/01/2004 enquanto que as observações mais destacadas da cauda esquerda correspondem às datas de 31/07/2001, 20/12/2001, 04/01/2002 e 26/05/20039/1998. 


\section{Capítulo 4}

\section{Modelos de Estimativas de Volatilidade}

Ressaltamos, inicialmente, que a volatilidade de ativos financeiros não é medida diretamente, podendo ser definida como sendo uma medida da variabilidade dos preços de ativos financeiros, implicando em um risco ao qual um investimento está exposto às possíveis mudanças nas conjunturas de mercados financeiros e crises econômicas.

Nesse sentido, tornam-se fundamentais estudos visando obter estimativas de volatilidade por meio de modelos estatísticos.

Considerando uma série de retornos como obtida em $r_{t}^{c}$, a qual denotaremos, por simplicidade, como $r_{t}$, sejam:

$\mu_{t}=E_{t-1}\left[r_{t}\right]$, como sendo a média condicional de $r_{t}$, dada a informação até $t-1$.

$\sigma_{t}^{2}=E_{t-1}\left[\left[r_{t}-\mu_{t}\right]^{2}\right]$, como sendo a variância condicional de $r_{t}$, dada a informação até $t-1$.

$\mu_{t}=E\left[r_{t}\right]$, como sendo a média não condicional de $r_{t}$, para todo $t$.

$\sigma^{2}=\operatorname{Var}\left[r_{t}\right]$, como sendo a variância não condicional de $r_{t}$, para todo $t$.

Modelo comum para volatilidade:

$r_{t}=\mu_{t}+\sqrt{\sigma_{t}^{2}} \epsilon_{t}$, onde:

$E_{t-1}\left[\epsilon_{t}\right]=0$ e $\operatorname{Var}_{t-1}\left[\epsilon_{t}\right]=1$ com $\epsilon_{t}$ tipicamente i.i.d. com certa distribuição.

$\mu_{t} \rightarrow$ indica o valor esperado de $r_{t}$ no instante $t$, sendo que em sua modelagem outros fatores podem ser incorporados, como por exemplo efeito autoregressivo.

$\sigma_{t} \rightarrow$ denominada volatilidade dos retornos.

Para estimar a volatilidade de séries de retornos existem vários modelos estatísticos. Anteriormente à década de 1980, os modelos mais utilizados eram os de média móvel e o de amortecimento exponencial e, a partir de trabalho de Engle (1982) - quando demonstrou que a heterocedasticidade pode ocorrer para dados como o de mercado de ações, formulando a noção de que dados do passado recente poderiam trazer mais informações sobre a variância condicional de hoje e ainda, que quanto mais recente fosse o distúrbio do passado observado, mais peso seria dado a ele no cálculo da variância condicional de hoje - cujos modelos estudados foram inicialmente denominados de modelos ARCH 
(Autoregressive Conditional Heterocedasticity), outras variações do modelo foram sendo propostas por vários autores como, por exemplo, GARCH (Generalized Autoregressive Conditional Heterocedasticity), IGARCH (GARCH Integrado), EGARCH (GARCH Exponencial), AGARCH (GARCH Assimétrico) e outras, formando os modelos da família ARCH/GARCH. Outra maneira de se obter a estimativa da volatilidade de séries de retornos é por meio do modelo de volatilidade estocástica, proposta por Taylor em 1980, o qual apresentaremos, juntamente com modelagem GARCH e modelagem por meio de média móvel da variabilidade histórica da amostra de retornos, os quais foram utilizados para a obtenção das estimativas de volatilidade das séries analisadas neste trabalho.

\subsection{Modelo de Volatilidade Estocástica}

Para os cálculos computacionais das estimativas de volatilidade de séries de ativos financeiros fizemos uso do programa STAMP (Koopman et al, 1995) e, neste capítulo, um dos objetivos, após o estudo da concepção teórica do modelo de volatilidade estocástica, é mostrar como esse programa procede. Para tanto, descreveremos todos os passos do modelo de volatilidade estocástica, partindo de sua concepção inicial.

\subsubsection{Suposição teórica inicial}

O modelo de volatilidade estocástica não faz a suposição de que a variância condicional dependa de retornos passados como nos modelos de volatilidade determinística, usa como premissa o fato de que a volatilidade depende de seus valores passados independentemente dos retornos passados, isto é, nesse modelo o conjunto de informações não é definido por $r_{t-1}$ (informações passadas), mas por um processo estocástico ${ }^{1}$ não observado, " $h_{t}$ ", que representa o fluxo de novas informações absorvido pelo mercado financeiro.

\subsubsection{Definição do modelo de volatilidade estocástica}

Considerando a série de retornos " $r_{t}$ " e " $\sigma_{t}^{2}$ ", a sua variância condicional, a série " $r_{t}$ "é dita um processo que segue um modelo de volatilidade estocástica se:

\footnotetext{
${ }^{1}$ Processo estocástico: Qualquer variável cujo valor mude de maneira incerta com o tempo segue um processo estocástico, que pode ser classificado como em tempo discreto ou em tempo contínuo. Em um processo estocástico em tempo discreto, o valor da variável pode mudar apenas em determinados pontos fixos no tempo, enquanto que em um processo estocástico em tempo contínuo, as mudanças podem ocorrer a qualquer tempo.Os processos estocásticos descrevem a evolução probabilística do valor de uma variável no tempo.
} 


$$
r_{t}=\sigma_{t} \epsilon_{t} \quad \text { e } \quad h_{t}=\ln \left(\sigma_{t}^{2}\right)
$$

onde:

$\epsilon_{t}$ é uma seqüência estacionária com média zero e variância 1.

$h_{t}$ é denominada log-volatilidade e, em sua concepção mais simples, é suposta como um processo autoregressivo de ordem 1 e é dado por:

$$
h_{t}=\gamma_{0}+\gamma_{1} h_{t-1}+\eta_{t}
$$

na qual:

$\gamma_{0}$ e $\gamma_{1}$ são parâmetros fixos nos tempo.

$\eta_{t}$ é uma seqüência estacionária com média zero e variância $\sigma_{\eta}^{2}$.

Ainda, no modelo em questão, assume-se que $\epsilon_{t}$ e $\eta_{t}$ são independentes e, para que $h_{t}$ seja estacionário, $\left|\gamma_{1}\right|<1$.

Para obtenção da equação inicial do modelo em uma forma linear procede-se à transformação logaritmo do quadrado do processo.

Aplicando um pouco de algebrismo à equação 4.1 do processo, formulada inicialmente:

$\left.r_{t}=\sigma_{t} \epsilon_{t} \rightarrow r_{t}=\exp \left(\frac{h_{t}}{2}\right) \epsilon_{t} \rightarrow r_{t}^{2}=\exp \left(h_{t}\right) \epsilon_{t}^{2} \rightarrow \ln \left(r_{t}^{2}\right)=\ln \left(\exp \left(h_{t}\right)\right) \epsilon_{t}^{2}\right) \rightarrow \ln \left(r_{t}^{2}\right)=$ $\ln \left(\exp \left(h_{t}\right)\right)+\ln \left(\epsilon_{t}^{2}\right) \rightarrow \ln \left(r_{t}^{2}\right)=\ln \left(\epsilon_{t}^{2}\right)+h_{t}$.

Substituindo $\ln \left(r_{t}^{2}\right)$ por $\omega_{t}$ e $\ln \left(\epsilon_{t}^{2}\right)$ por $\xi_{t}$ tem-se que:

$$
\omega_{t}=\xi_{t}+h_{t}
$$

que é denominada de equação do modelo de volatilidade estocástica na forma linear.

\subsubsection{Propriedades do modelo}

\section{Média do processo $r_{t}$}

Da suposição inicial de independência entre $\epsilon_{t}$ e $\eta_{t}$, segue que $\sigma_{t}=\exp \left(\frac{h_{t}}{2}\right)$ e $\epsilon_{t}$ também o são; daí:

$E\left[r_{t}\right]=E\left[\sigma_{t} \epsilon_{t}\right]=E\left[\sigma_{t}\right] E\left[\epsilon_{t}\right]=0$, isto é, a média do processo é igual a zero. 


\section{Variância do processo $r_{t}$}

$\operatorname{Var}\left[r_{t}\right]=E\left[r_{t}^{2}\right]-\left(E\left[r_{t}\right]\right)^{2}=E\left[r_{t}^{2}\right]=E\left[\sigma_{t}^{2} \epsilon_{t}^{2}\right]=E\left[\sigma_{t}^{2}\right] E\left[\epsilon_{t}^{2}\right]=E\left[\sigma_{t}^{2}\right] \operatorname{Var}\left[\epsilon_{t}\right]=E\left[\sigma_{t}^{2}\right]$

Assim, como $\sigma_{t}^{2}$ é dada em função de $h_{t}$, obtém-se a variância de $\sigma_{t}^{2}$, conhecendo-se a variância de $h_{t}$.

Da concepção de $h_{t}$ como sendo um processo autoregressivo de ordem 1, dado por: $h_{t}=\gamma_{0}+\gamma_{1} h_{t-1}+\eta_{t}$ no qual $\gamma_{0}$ e $\gamma_{1}$ são parâmetros fixos nos tempo e $\eta_{t}$ é uma seqüência estacionária normalmente distribuída com média zero e variância $\sigma_{\eta}^{2}$, temos que $h_{t}$ tem distribuição normal onde:

$E\left[h_{t}\right]=\frac{\gamma_{0}}{1-\gamma_{1}}$

$\operatorname{Var}\left[h_{t}\right]=\frac{\sigma_{\eta}^{2}}{1-\gamma_{1}^{2}}$

Assim, sua distribuição é dada por $h_{t} \sim N\left(\frac{\gamma_{0}}{1-\gamma_{1}}, \frac{\sigma_{\eta}^{2}}{1-\gamma_{1}^{2}}\right)$

Dessa forma, como $h_{t}=\ln \left(\sigma_{t}^{2}\right)$ segue que $\sigma_{t}^{2}$ tem distribuição lognormal, com o k-ésimo momento central dado por:

$M_{k}=\exp \left(k \mu_{h}+\frac{\sigma_{\eta}^{2}}{2}\right)$, onde:

$\sigma_{h}^{2}$ é a variância de $h_{t}$

$\mu_{h}$ é a média de $h_{t}$

Nessas condições, o processo $r_{t}$ tem seus momentos de ordem ímpar nulos, dado que a sua distribuição é simétrica em torno de zero e os de ordem par dados pela expressão acima citada.

Então, a variância não condicional de $r_{t}$ no modelo é:

$\operatorname{Var}\left[r_{t}\right]=E\left[r_{t}^{2}\right]=E\left[\sigma_{t}^{2}\right]=\exp \left(\frac{\gamma_{0}}{1-\gamma_{1}}+\frac{\sigma_{\eta}^{2}}{2\left(1-\gamma_{1}^{2}\right)}\right)$

\section{Função de auto-covariância da série $r_{t}$}

Da suposição do modelo de que as variáveis aleatórias $\epsilon_{t}$ e $\eta_{t}$ são independentes, aliado ao fato de que a média do processo é zero, segue que:

$$
E\left[r_{t} r_{t+k}\right]=E\left[\left(\sigma_{t} \epsilon_{t}\right)\left(\sigma_{t+k} \epsilon_{t+k}\right)\right]=E\left[\left(\sigma_{t} \sigma_{t+k}\right)\left(\epsilon_{t} \epsilon_{t+k}\right)\right]=0
$$

Assim, para qualquer $k>0$, o processo $r_{t}$ é serialmente não correlacionado, porém não é independente pois há correlação na transformação logaritmo do quadrado do processo (equação do processo na forma linear), pois a função de auto-correlação de $\omega_{t}=\ln \left(r_{t}^{2}\right)$ é dada por:

$$
\rho_{\omega}(k)=\frac{\gamma_{1}^{k}}{1+\frac{\pi^{2}}{2 \sigma_{h}^{2}}}, k>0, \text { a qual decai exponencialmente a partir do lag } k=2 .
$$


Da estrutura do modelo, destaca-se que a distribuição de $r_{t}$ tem caudas pesadas e, devido à sua estrutura autoregressiva, gera agrupamentos de volatilidade. As evidências empíricas na estimação do modelo são de que $\gamma_{1}$ é muito próximo a 1 implicando em alta persistência ou mesmo memória longa da série.

$\mathrm{Na}$ modelagem de volatilidade estocástica, de que trata esta seç̧ão, o programa computacional quc utilizamos para a obtenção das estimativas de volatilidade dos retornos dos ativos financeiros - Stamp -Koopman et al., 1995 - fornece os estimadores de quase-máxima verossimilhança do modelo, escrito na forma de Espaço de Estados, por intermédio de uma técnica conhecida como o Filtro de Kalman, que descreveremos adiante e, posteriormente, adequaremos essa técnica considerando as equações 4.3 e 4.2 do modelo de volatilidade estocástica na forma linear, que podem ser tratadas como equações de um modelo de Espaço de Estados.

\subsubsection{Forma de Espaço-Estado de uma série}

A metodologia inicial da forma de Espaço-Estado de uma série foi desenvolvida inicialmente por Kalman (1960), publicada em um artigo de uma revista de Engenharia de Controle. Após 1980 muitos estatísticos produziram trabalhos sobre essa metodologia. É considerada bastante relevante no sentido de que a representação de uma série na forma de Espaço-Estado permite que vários componentes de uma série sejam modelados separadamente e, ainda, pela natureza Markoviana ${ }^{2}$ do modelo, os cálculos necessários podem ser colocados de forma recursiva que, juntamente com técnicas computacionais, permite modelar diretamente mudanças na estrutura do sistema no decorrer do tempo.

$\mathrm{O}$ modelo de espaço de estados para uma série temporal multivariada $y_{t}$, contendo $N$ elementos, é representado, em geral, pelas seguintes equações:

$$
y_{t}=Z_{t} \alpha_{t}+W_{t}
$$

que é denominada equação de medida e,

$$
\alpha_{t}=T_{t} \alpha_{t-1}+V_{t}
$$

que é denominada equação de transição, onde:

$y_{t}:(N \times 1) \rightarrow$ série temporal multivariada.

$Z_{t}:(N \times m) \rightarrow$ matriz que relaciona o estado com a série $y_{t}$.

$\alpha_{t}:(m \times 1) \rightarrow$ vetor de estado do processo - não observável, gerado por um processo de Markov de primeira ordem.

$W_{t}:(N \times 1) \rightarrow$ vetor de distúrbios com $E\left[W_{t}\right]=0$ e $\operatorname{Var}\left[W_{t}\right]=R_{t}$ - ruído branco, serialmente não correlacionado.

\footnotetext{
${ }^{2}$ Processo de Markov: é um processo estocástico em que apenas o valor atual da variável é relevante para prever o futuro. O histórico de uma variável e a forma como o presente emergiu do passado são irrelevantes.
} 
$T_{t}:(m \times m) \rightarrow$ matriz que relaciona o estado com o estado anterior.

$V_{t}:(m \times 1) \rightarrow$ vetor de distúrbios com $E\left[V_{t}\right]=0$ e $\operatorname{Var}\left[V_{t}\right]=Q_{t}$ - ruído branco, serialmente não correlacionado.

Para completar as características do modelo de Espaço-Estado são necessárias algumas suposições:

a - Os distúrbios $W_{t}$ e $V_{t}$ são geralmente distribuídos independentemente um do outro para todo o período de tempo, isto é, $E\left[W_{t} V_{t}^{\prime}\right]=0$ para todo $t$ e $s$.

b - Os distúrbios $W_{t}$ e $V_{t}$ são distribuídos independentemente de $\alpha_{0}$ - estado inicial da variável $\alpha_{t}$, isto é, $E\left[W_{t} \alpha_{0}^{\prime}\right]=0$ e $E\left[V_{t} \alpha_{0}^{\prime}\right]=0$.

c - O vetor do estado inicial $\alpha_{0}$ tem $E\left[\alpha_{0}\right]=a_{0}$ e $\operatorname{Var}\left[\alpha_{0}\right]=P_{0}$.

Dada essas especificações para modelos na forma de espaço-estado, podemos observar que esse sistema é linear.

\section{O Filtro de Kalman}

O filtro de Kalman é um procedimento recursivo utilizado para a obtenção do estimador do vetor de estado em $t$ - $\alpha_{t}$ - baseado nas observações disponíveis de $y_{1}, y_{2}, \ldots, y_{t-1}$.

Para se obter o estimador assume-se que as matrizes do sistema, juntamente com $a_{0}$ e $P_{0}$, valor esperado e matriz de covariância do vetor de estado inicial $\alpha_{0}$, respectivamente, são conhecidos em todos os períodos de tempo.

Sejam $a_{t-1}$ o estimador de $\alpha_{t-1}$ e $P_{t-1}$ a matriz de covariância do erro de estimação. Então, $P_{t-1}=E\left[\left(\alpha_{t-1}-a_{t-1}\right)\left(\alpha_{t-1}-a_{t-1}\right)^{\prime}\right]$

Dessa forma, conhecendo-se $a_{t-1}$ e $P_{t-1}$, o estimador para $\alpha_{t}, a_{t / t-1}$, é dado por:

$a_{t / t-1}=E\left[\alpha_{t / t-1}\right]=E\left[\alpha_{t}=T_{t} \alpha_{t-1}+V_{t}\right]=E\left[T_{t} \alpha_{t-1}\right]+E\left[V_{t}\right]=T_{t} E\left[\alpha_{t-1}\right]+0=T_{t} a_{t-1}$

Assim, a equação:

$$
a_{t / t-1}=T_{t} a_{t-1}
$$

é denominada de Predição de $\alpha_{t}$.

A matriz de covariância da estimação do erro é dada por:

$$
\begin{aligned}
& \quad P_{t / t-1}=E\left[\left(\alpha_{t}-a_{t}\right)\left(\alpha_{t}-a_{t}\right)^{\prime}\right] \\
& P_{t / t-1}=E\left[\left(T_{t} \alpha_{t-1}+V_{t}-T_{t} a_{t-1}\right)\left(T_{t} \alpha_{t-1}+V_{t}-T_{t} a_{t-1}\right)^{\prime}\right] \\
& P_{t / t-1}=E\left[\left(T_{t}\left(\alpha_{t-1}-a_{t-1}\right)+V_{t}\right)\left(T_{t}\left(\alpha_{t-1}-a_{t-1}\right)+V_{t}\right)^{\prime}\right] \\
& P_{t / t-1}=E\left[\left(T_{t}\left(\alpha_{t-1}-a_{t-1}\right)\right)\left(T_{t}\left(\alpha_{t-1}-a_{t-1}\right)\right)^{\prime}\right]+E\left[\left(V_{t}\right)\left(V_{t}\right)^{\prime}\right] \rightarrow \text { pela premissa do modelo }
\end{aligned}
$$


de não correlacionamento entre $V_{t}$ e $\left(\alpha_{t-1}-a_{t-1}\right)$

$P_{t / t-1}=T_{t} E\left[\left(\alpha_{t-1}-a_{t-1}\right)\left(\alpha_{t-1}-a_{t-1}\right)^{\prime}\right] T_{t}^{\prime}+\operatorname{Var}\left[V_{t}\right]$

$P_{t / t-1}=T_{t} P_{t-1} T_{t}^{\prime}+Q_{t}$

Estando disponível uma nova informação $y_{t}$, o estimador de $\alpha_{t}-a_{t / t-1}$, pode ser atualizado. A cquação:

$$
a_{t / t}=a_{t / t-1}+K_{t}\left(y_{t}-y_{t-1}\right)
$$

que é denominada de atualização de $\alpha_{t}$, onde $K_{t}$ é chamada Matriz de ganho de Kalman.

A equação de atualização para a matriz de covariância ${ }^{3}$ é dada por:

$$
P_{t / t}=P_{t / t-1}\left(1-K_{t} Z_{t}\right)
$$

As equações de predição e de atualização formam o conjunto recursivo do filtro de Kalman.

Dessa forma, as equações do modelo de volatilidade estocástica $4.3\left(\omega_{t}=\xi_{t}+h_{t}\right)$ e 4.2 $\left(h_{t}=\gamma_{0}+\gamma_{1} h_{t-1}+\eta_{t}\right)$ são semelhantes, respectivamente, às equações $4.4\left(y_{t}=Z_{t} \alpha_{t}+W_{t}\right)$ e $4.5\left(\alpha_{t}=T_{t} \alpha_{t-1}+V_{t}\right)$ do filtro de Kalman, onde a correspondência entre as variáveis é traduzida na tabela abaixo.

\begin{tabular}{|l|c|}
\hline Variáveis do modelo de V.Est. & Variáveis da eq. Espaço-Estado(f.Kalman) \\
\hline \hline$\omega_{t}$ & $y_{t}$ \\
\hline$\xi_{t}$ & $W_{t}$ \\
\hline$h_{t}$ & $\alpha_{t}$ \\
\hline$\gamma_{0} \& \gamma_{1}$ & $T_{t}$ \\
\hline$\eta_{t}$ & $V_{t}$ \\
\hline
\end{tabular}

onde as matrizes do sistema são dadas por:

$$
Z_{t}=\left[\begin{array}{ll}
0 & 1
\end{array}\right] \quad \text { e } \quad T_{t}=\left[\begin{array}{cc}
1 & 0 \\
\gamma_{0} & \gamma_{1}
\end{array}\right]
$$

Assim, a representação do modelo de volatilidade estocástica na forma de Espaço-Estado terá as seguintes equações de medida e transição, respectivamente:

$$
\begin{gathered}
r_{t}=\left[\begin{array}{ll}
0 & 1
\end{array}\right] \times\left[\begin{array}{c}
1 \\
h_{t}
\end{array}\right]+\xi_{t} \\
{\left[\begin{array}{c}
1 \\
h_{t}
\end{array}\right]=\left[\begin{array}{cc}
1 & 0 \\
\gamma_{0} & \gamma_{1}
\end{array}\right] \times\left[\begin{array}{c}
1 \\
h_{t-1}
\end{array}\right]+\left[\begin{array}{c}
0 \\
\eta_{t}
\end{array}\right]}
\end{gathered}
$$

$\mathrm{Na}$ prática, na análise de séries de retornos, algumas observações podem ser nulas, o que

\footnotetext{
${ }^{3}$ A demonstração dessa equação é oferecida em várias obras, como por exemplo, por: Shumway, R. H. and Stoffer, D. S. 2000 . Time Series Analysis and Its Applications, New York: Springer
} 
impediria a transformação logaritmo do quadrado do processo especificada anteriormente $\left(\ln \left(r_{t}^{2}\right)=\omega_{t}\right)$. Uma solução sugerida por Fuller e revista por Breidt e Carriquiry (1996), baseada numa expansão de Taylor, é fazer a seguinte transformação:

$$
\ln \left(r_{t}^{2}\right)=\ln \left(r_{t}^{2}+c S_{r}^{2}\right)-\frac{c S_{r}^{2}}{r_{t}^{2}+c S_{r}^{2}}
$$

onde $S_{r}^{2}$ é a variância amostral da série $r_{t}$ e $c$ é um número pequeno.

Neste trabalho utilizamos o programa computacional Stamp, o qual incorpora a transformação sugerida por Fuller utilizando um valor default $c=0.02 \mathrm{e}$ fornece os estimadores de quase máxima verossimilhança dos parâmetros do modelo , escrito na forma de EspaçoEstado.

\subsection{Modelo de Volatilidade - Método GARCH}

O uso de modelos GARCH (Generalized Autoregressive Conditional Heterocedasticity) deve-se, principalmente, à crença convencional referente às características frequentemente observadas em ativos financeiros de que a variância dos retornos não é constante e pela presença de aglomerados de volatilidade, fatos indicativos de heterocedasticidade dessas séries.

O modelo GARCH foi sugerido por Bollerslev (1986) como uma generalização dos modelos ARCH(Autoregressive Conditional Heterocedasticity), introduzidos por Engle (1982), cuja suposição fundamental é que os retornos $r_{t}$ são serialmente não correlacionados mas a volatilidade depende de retornos passados por intermédio de uma função quadrática.

\subsubsection{Definição do Modelo GARCH a partir da Generalização do modelo ARCH}

$\mathrm{O}$ modelo $\mathrm{ARCH}(\mathrm{p})$, inicialmente proposto, é definido por:

$$
r_{t}=\sqrt{h_{t}} \epsilon_{t} \quad \text { e } \quad h_{t}=\alpha_{0}+\alpha_{1} r_{t-1}^{2}+\ldots+\alpha_{p} r_{t-p}^{2}
$$

que, em sua concepção mais simples, $(p=1)$, define o modelo $\operatorname{ARCH}(1)$, pela equação:

$$
r_{t}=\sqrt{h_{t}} \epsilon_{t} \quad \text { e } \quad h_{t}=\alpha_{0}+\alpha_{1} r_{t-1}^{2}
$$

com as seguintes restrições:

$\epsilon_{t}$ é um ruído branco, ou seja, $\epsilon_{t} \sim \operatorname{iid}(0,1)$.

$\alpha_{0}$ e $\alpha_{1}$, parâmetros do modelo, tais que $\alpha_{0}>0$ e $\alpha_{1} \geq 0$.

$\alpha_{1}<1$, para que o modelo seja estacionário.

Considerando o modelo na forma geral, dado pela equação 4.10, tem-se que, além dos 
parâmetros $\alpha_{i}$, o modelo possui o parâmetro $p$, indicador da ordem de autoregressão para ser estimado.

$\mathrm{O}$ modelo GARCH, além de ser uma generalização do modelo $\mathrm{ARCH}$, é também tido como uma forma mais parcimoniosa de expressá-los, principalmente daqueles com muitos parâmetros $(p>1)$.

$\mathrm{O}$ modelo $\operatorname{GARCH}(p, q)$ é definido por:

$$
r_{t}=\sqrt{h_{t}} \epsilon_{t} \quad \text { e } \quad h_{t}=\alpha_{0}+\sum_{i=1}^{p} \alpha_{i} r_{t-i}^{2}+\sum_{j=1}^{q} \beta_{j} h_{t-j}
$$

com as seguintes restrições:

$\epsilon_{t}$ é um ruído branco, ou seja, $\epsilon_{t} \sim i i d(0,1)$.

$\alpha_{0}, \alpha_{i}$ e $\beta_{j}$,parâmetros do modelo, tais que $\alpha_{0}>0, \alpha_{i} \geq 0$ e $\beta_{j} \geq 0$.

$\left(\sum_{i=1}^{p} \alpha_{i}+\sum_{j=1}^{q} \beta_{j}\right)<0$, para que o modelo seja estacionário.

$\mathrm{Na}$ prática, o modelo $\operatorname{GARCH}(\mathrm{p}, \mathrm{q})$ com $p=q=1$, é um dos mais utilizados, caso este em que a volatilidade $h_{t}$ é dada por meio da equação:

$$
h_{t}=\alpha_{0}+\alpha_{1} r_{t-1}^{2}+\beta_{1} h_{t-1}
$$

\subsection{Modelo de Volatilidade - Método Média Móvel da Variabilidade da Amostra}

Este modelo utiliza uma janela fixa $m$ na estimação da volatilidade, isto é, para a estimativa no instante $t$ é agregada a observação do instante $t-1$ e desconsiderada a informação do instante $t-(m+1)$. É considerado, embora bastante empregado, o mais simples e apresenta algumas desvantagens, quais sejam:

a - Despreza a ordenação dinâmica das observações, ou seja, é atribuído o mesmo peso às observações, tanto às mais recentes quanto às mais antigas, apesar de que, provavelmente, as mais recentes sejam mais relevantes.

b - Quando um retorno grande é desconsiderado, conforme a janela, a previsão de volatilidade é afetada repentinamente e, em um único instante.

\subsubsection{Definição do Modelo Média Móvel da Variabilidade da Amostra - M.M.V.A}

A fórmulação básica deste método é dada pela equação:

$$
\hat{\sigma}_{t}^{2}=\frac{1}{m} \sum_{j=1}^{m}\left(r_{t-j}-E\left[r_{t}\right]\right)^{2}=\frac{1}{m} \sum_{j=1}^{m} r_{t-j}^{2}
$$

visto que a série $r_{t}$ é construída de tal forma que $E\left[r_{t}\right]=0$ 
Outro problema presente neste método é o tamanho da janela, posto que tamanhos diferentes de janela conduzem a valores distintos de estimativas de volatilidade. A escolha da janela móvel não tem uma definição uma regra rígida, embora podemos destacar o fato de que períodos mais longos podem levar a estimativas mais precisas, porém podem não captar variações que seriam observadas em períodos menores.

Tal escolha do tamanho $m$ da janela pode utilizar dois mecanismos, quais sejam:

a - definição arbitrária e, neste caso, os valores mais comuns para as janelas são $m=20$, 40 ou 60.

b - escolha da janela ótima com o uso do método dos mínimos quadrados, cujo procedimento sintetizado descrevemos abaixo:

\section{Descrição do procedimento para obtenção da janela ótima}

O procedimento que utilizamos foi o seguinte:

1- Estabelecemos o valor mínimo $(m=10)$ e o máximo ( $m=\frac{1}{3}$ do tamanho da amostra).

2- Calculamos o valor da previsão de volatilidade para $d+1$, utilizando a equação $\hat{\sigma}_{t}^{2}=\frac{1}{m} \sum_{j=1}^{m}\left(r_{t-j}-E\left[r_{t}\right]\right)^{2}=\frac{1}{m} \sum_{j=1}^{m} r_{t-j}^{2}$ (equação 4.14 ) com $m=10$.

3- Avançamos a janela até ( $m=\frac{1}{3}$ do tamanho da amostra) e repetimos o passo 2 .

4- Calculamos o erro de previsão por meio da expressão:

$E=\sqrt{\frac{\sum_{i=1}^{N}\left(r_{t}^{2}-\hat{\sigma}_{i}^{2}\right)^{2}}{N}}$

5- Adotamos como o tamanho ótimo para a janela aquele com o menor valor de erro de previsão.

Escolhido o tamanho da janela, basta aplicarmos o método, usando a equação 4.14 para obter as estimativas de volatilidade.

Em nosso trabalho, após executarmos testes para tamanhos de janelas correspondentes aos dois mecanismos, optamos em apresentar resultados obtidos pela janela $m=24 \mathrm{em}$ função de não encontrarmos uma janela ótima comum às séries de retornos dos ativos em estudo e, ainda, por ser essa janela, ainda que em escalas diferentes, a que forneceu estimativas mais coerentes, relativamente às outras duas modelagens utilizadas neste trabalho. 


\subsection{Análise das estimativas de volatilidade dos ativos segundo os métodos de modelagem adotados}

Obtidas as séries de retornos como o exposto no Capítulo anterior, procedemos ao cálculo das estimativas de volatilidade dos retornos dos ativos utilizando o modelo de Volatilidade Estocástica, modelo GARCH e o modelo M.M.V.A., utilizando-se os programas computacionais STAMP, EVIEWS e EXCEL, respectivamente.

Apresentamos os resultados obtidos das estimativas obtidas pelos modelos para os ativos Ibovespa, Dólar, Taxa Pré e Taxa Cupom, comparamos os resultados das modelagens e analisamos a capacid̦ade de previsão ${ }^{4}$ de cada modelo. Ressaltamos, novamente, que no período em estudo ocorreram fatos atípicos no mercado financeiro influenciados pela crise da Rússia, crises do Real e queda da bolsa NASDAQ.

\footnotetext{
${ }^{4}$ Para a análise da capacidade de previsão dos modelos utilizamos os seus respectivos erros de previsão. Entretanto, como a volatilidade não é observável, fizemos uso do quadrado do retorno como sendo o representante de suas respectivas variâncias; este tendo sido adotado sem ter sido julgado ser ou não adequado por não ser o mesmo objeto de nossa análise
} 


\subsubsection{Ativo Ibovespa}

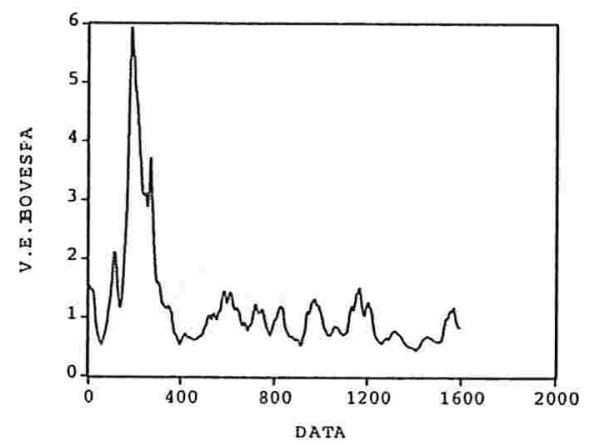

Figura 4.1: Estimativas de volatilidade obtidas pelo modelo de Volatilidade Estocástica - V.E.

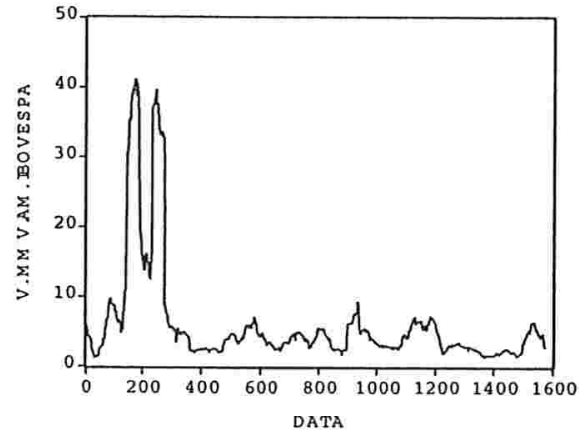

Figura 4.3: Estimativas de volatilidade obtidas pelo modelo Média Móvel da Variabilidade Amostral MMVA

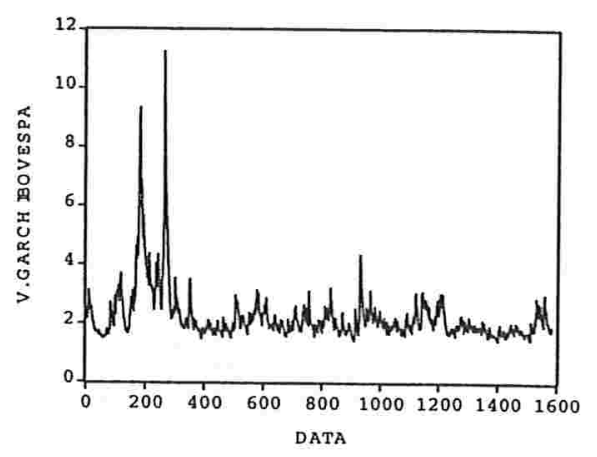

Figura 4.2: Estimativas de volatilidade obtidas pelo modelo $\operatorname{GARCH}(1,1)$ 


\subsubsection{Ativo Dólar}

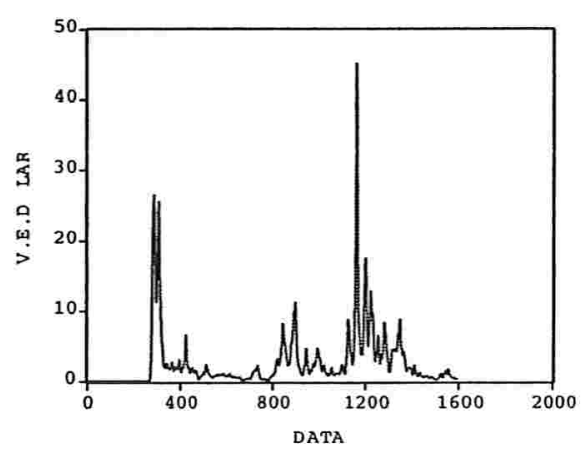

Figura 4.4: Estimativas de volatilidade obtidas pelo modelo de Volatilidade Estocástica - V.E.

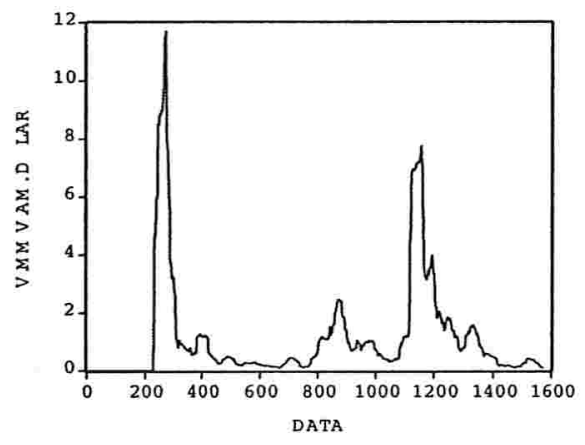

Figura 4.6: Estimativas de volatilidade obtidas pelo modelo Média Móvel da Variabilidade Amostral MMVA

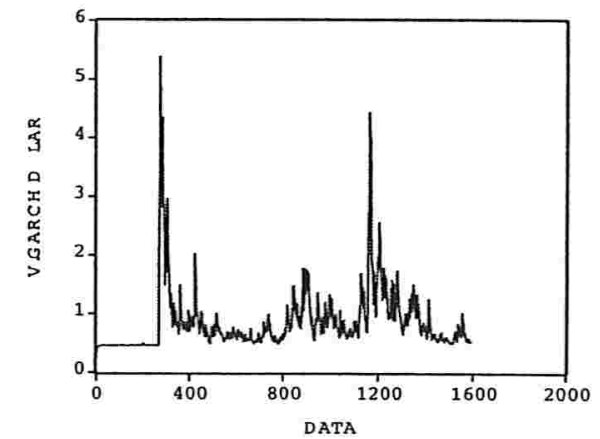

Figura 4.5: Estimativas de volatilidade obtidas pelo modelo $\operatorname{GARCH}(1,1)$ 


\subsubsection{Ativo Taxa Pré Juros}

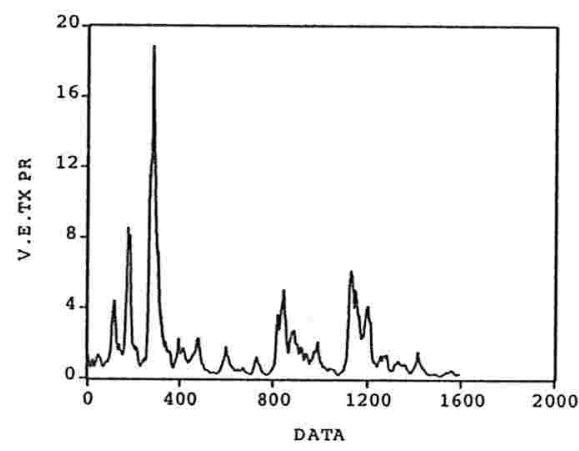

Figura 4.7: Estimativas de volatilidade obtidas pelo modelo de Volatilidade Estocástica - V.E.

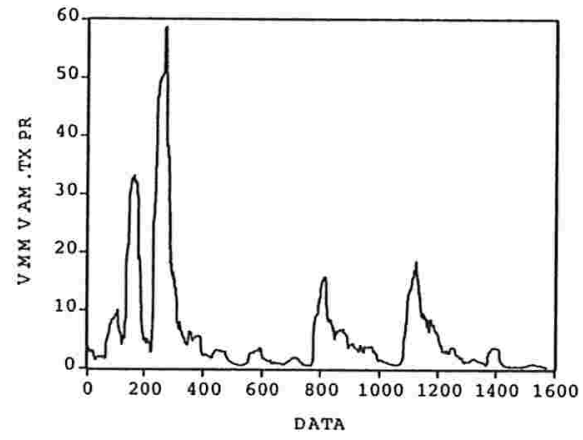

Figura 4.9: Estimativas de volatilidade obtidas pelo modelo Média Móvel da Variabilidade Amostral MMVA

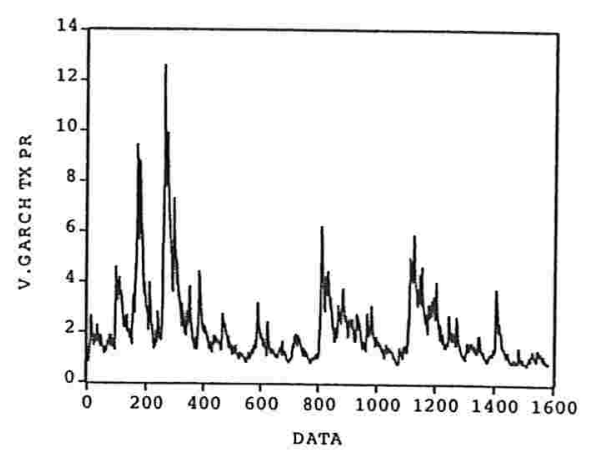

Figura 4.8: Estimativas de volatilidade obtidas pelo modelo $\operatorname{GARCH}(1,1)$ 


\subsubsection{Ativo Taxa Cupom Cambial}

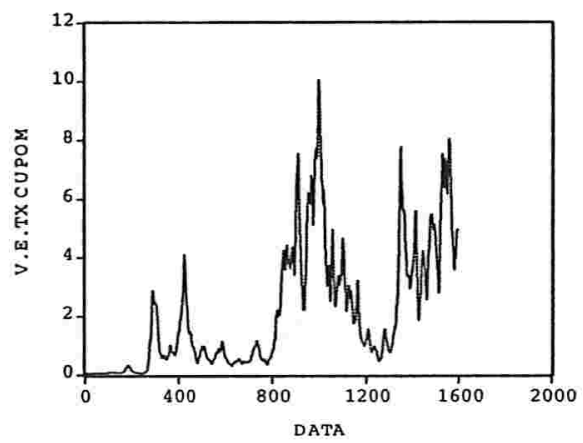

Figura 4.10: Estimativas de volatilidade obtidas pelo modelo de Volatilidade Estocástica - V.E.

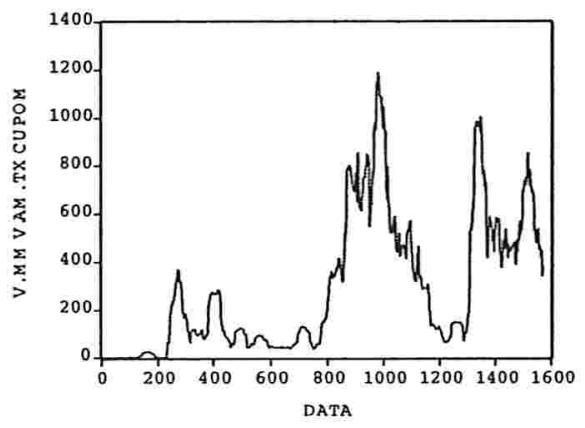

Figura 4.12: Estimativas de volatilidade obtidas pelo modelo Média Móvel da Variabilidade Amostral MMVA

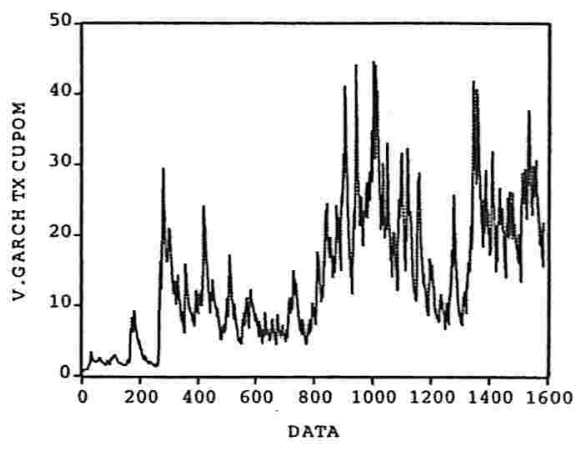

Figura 4.11: Estimativas de volatilidade obtidas pelo modelo $\operatorname{GARCH}(1,1)$ 


\subsubsection{Análise das Estimativas de Volatilidade Obtidas}

As estimativas de volatilidade de cada modelo, em que pese serem valores em escalas diferentes, apresentaram comportamentos similares.

Quanto à capacidade de previsão dos modelos constatamos que o modelo de Volatilidade Estocástica apresentou menor erro relativamente aos outros dois e captaram as situações atípicas do mercado financeiro ocorridas no período, como por exemplo:

- A moratória da Rússia (agosto de 1998) e a crise do Real (janeiro de 1999) foram os fatores mais influentes nas estimativas de volatilidade (dados à direita da observação 150 e à esquerda da observação 300 , respectivamente)

- A queda da Bolsa Nasdaq (abril de 2000) e a crise do Real (setembro de 2000) também tiveram influência, embora não acentuadamente (dados ầ esquerda da observação 600 e à esquerda da observação 1200, respectivamente).

- A desvalorização do Real (janeiro de 1999) influenciou sensivelmente nas estimativas de volatilidade do Dólar (dados do intervalo entre as observações 225 e 300).

- A desvalorização do Real (setembro de 2002) foi o fator mais influente nas estimativas de volatilidade do Dólar no período estudado (dados à esquerda da observação 1200).

- A moratória da Rússia (agosto de 1998) teve reflexo acentuado nas estimativas de volatilidade da Taxa Pré (dados à direita da observação 150)

- As desvalorizações do Real (janeiro de 1999 e setembro de 2002) foram fatores bastante influentes nas estimativas de volatilidade da Taxa Pré (dados à esquerda da observação 300 e à esquerda da observação 1200).

- A desvalorização do Real (janeiro de 1999), dentre os fatores atípicos do período refletiu consideravelmente nas estimativas de volatilidade da Taxa Cupom Cambial (dados à esquerda da observação 300) visto que as estimativas anteriores a esse fato eram praticamente nulas. 


\section{Capítulo 5}

\section{Ensaio $\mathbf{n}^{0} \mathbf{1}$ - Caso Univariado: Análise dos Retornos de Ativos Financeiros Correspondentes a Faixas de Estimativas de Volatilidade Crescentes}

\subsection{Teoria de Valores Extremos - TVE}

Nesta Seç̧ão, exibimos conceitos e resultados da Teoria de Valores Extremos (TVE) que permitiram fazer a análise do comportamento das caudas das distribuições dos retornos dos ativos financeiros em estudo neste trabalho e apresentamos o método de estimação da cauda dos retornos denominado como Método de excedentes além de um limiar (POT Peakes over a threshold). A literatura utilizada para a composição desta sinopse é baseada em "Embrechts et al (1997)", considerada uma referência padrão sobre TVE.

\subsubsection{Resultado da TVE utilizado}

Considerando uma variável aleatória $X$ com função de distribuição $F$ e $X_{1}, X_{2}, \ldots$ uma sequência de variáveis aleatórias independentes e igualmente distribuídas também com função de distribuição $F$. Define-se:

$M_{n}=\max \left\{X_{1}, X_{2}, \ldots, X_{n}\right\}$ e $F_{M_{n}}$ a função de distribuição de $M_{n}$.

A TVE estuda a existência e as propriedades da distribuição limite das variáveis aleatórias $a_{n}+b_{n} \cdot M_{n}, n \in N$, onde $a_{n}, n \in N$ e $b_{n}, n \in N$ são sequências numéricas escolhidas adequadamente. Para o resultado da convergência dos máximos é necessária a definição: Para cada $\gamma \in R$, seja a função de distribuição $H_{\gamma}$ :

$$
H_{\gamma}(x)=\left\{\begin{array}{rlr}
e^{-(1+\gamma x)^{-1 / \gamma},} & \text { se } & \gamma \neq 0 \\
e^{-e^{-x}}, & \text { se } & \gamma=0
\end{array}\right.
$$


para $x$ da região $\{x: 1+\gamma x>0\}$ e, para $x$ fora desta região, $H_{\gamma}$ deve ser completada por 0 ou 1 para que seja função de distribuição.

$\left\{H_{\gamma}, \quad \gamma \in R\right\}$ é chamada de família de distribuições generalizadas de valores extremos (Generalized Extreme Values distributions - GEV), nome esse decorrente do teorema a seguir, o qual é uma coletânea dos Teorema 3.2 .3 e 3.4.5 apresentados em "P. Embrechts, C. Kluppelberg e T. Mikosch. Modelling Extremal Events for Insurance and Financc. Springwer, Berlin, 1997.":

Teorema 1.As propriedades $i$ e $i i$ são equivalentes: se uma é válida, a outra também é.

(i) Existem as sequências numéricas $a_{n}$ e $b_{n}$, os números reais $\gamma, \nu$ e $\delta$, de tal forma que $F_{a_{n}+b_{n} M_{n}}(x), x \in R$, função de distribuição da v.a. $a_{n}+b_{n} M_{n}$, converge, quando $n \rightarrow \infty$, à função $H_{\gamma}(\nu+\delta x), x \in R$.

(ii) Existe o número real $\gamma$ e a função $\sigma: R^{+} \longrightarrow R^{+}$de tal forma que:

$$
\lim _{u \rightarrow x_{F}} \sup _{u \leq y \leq x_{F}}\left|P\left[\frac{X-u}{\sigma(u)} \leq y \mid X>u\right]-G_{\gamma}(y)\right|=0
$$

onde:

$$
G_{\gamma}(y)=\left\{\begin{aligned}
1-e^{-y}, & \text { se } \gamma=0 \\
1-(1+\gamma y)^{-1 / \gamma}, & \text { se } \gamma \neq 0
\end{aligned}\right.
$$

para $y$ da região $\{y: y \geq 0 e y \leq-1 / \gamma\}$, para $\gamma<0$, e da região $\{y: y \geq 0\}$,para $\gamma \geq 0$; para $y$ fora desta região, $G_{\gamma}$ deve ser completada por 0 ou 1 para que seja função de distribuição.

A função de distribuição $G_{\gamma}$ é denominada Distribuição de Pareto Generalizada (Generalized Pareto Distribution - GPD). Pela TVE tem-se que para qualquer escolha das sequências numéricas $a_{n}$ e $b_{n}$, a sequência de funções $F_{a_{n}+b_{n} M_{n}}(x), x \in R$, não converge para nenhuma função de distribuição, a não ser a degenerada, ou existem sequências numéricas $a_{n}$ e $b_{n}$ de tal forma que ocorre a convergência para uma função de distribuição cuja função limite é do tipo $H_{\gamma}$, isto é, pode ser obtida de $H_{\gamma}$ por transformação linear de seu argumento $x \rightarrow \nu+\delta x$, para números adequados $\nu$ e $\delta$. A propriedade (ii) do Teorema 1 é uma das condições suficientes e também necessária para garantir a convergência dos máximos.

O parâmetro $\gamma$ é dito índice de cauda para GPD, isto é, para $H_{\gamma}$ e, ocorrendo a convergência dos máximos, também será para $F$, a função de distribuição de $X$. Também é referido como índice de cauda no âmbito GEV, isto é, para $H_{\gamma}$, justificado pela equivalência entre $(i)$ e (ii) do Teorema 1, visto que o parâmetro $\gamma$ é o mesmo nas duas propriedades. Relativamente ao parâmetro $\gamma$ há três casos a serem considerados:

- $\gamma=0$. Neste caso a GPD é a função de distribuição exponencial de parâmetro 1. Ocorrendo a convergência dos máximos para esse valor diz-se que a distribuição da variável aleatóra $X$ possui cauda com decaimento exponencial, isto é, cauda fina. No Teorema 1 (ii) ocorre para $\gamma=0$ se e somente se existem as sequências $a_{n}$ e $b_{n}$ de tal forma que 
$F_{a_{n}+b_{n} M_{n}}$ converge para uma GEV com o mesmo parâmetro $\gamma=0$ e, uma GEV dessa forma tem o tipo da distribuição Gumbel.

- $\gamma<0$. Neste caso a GPD é a função de distribuição Beta. Ocorrendo a convergência dos máximos para esses valores diz-se que $x_{F}$ é finito, ou seja, a distribuição da variável aleatóra $X$ é sem cauda. No Teorema 1 (ii) ocorre para $\gamma<0$ se e somente se existem as sequências $a_{n}$ e $b_{n}$ de tal forma que $F_{a_{n}+b_{n} M_{n}}$ converge para uma GEV com o mesmo parâmetro $\gamma$ e, uma GEV dessa forma tem o tipo da distribuição Weibull de parâmetro $\alpha=-1 / \gamma$.

- $\gamma>0$. Neste caso a GPD é a função de distribuição de Pareto. Ocorrendo a convergência dos máximos para esses valores diz-se que a distribuição da variável aleatóra $X$ possui cauda com decaimento por uma potência, ou seja cauda grossa. No Teorema 1 (ii) ocorre para $\gamma>0$ se e somente se existem as sequências $a_{n}$ e $b_{n}$ de tal forma que $F_{a_{n}+b_{n} M_{n}}$ converge para uma GEV com o mesmo parâmetro $\gamma$ e, uma GEV dessa forma tem o tipo da distribuição de Fréchet de parâmetro $\alpha=1 / \gamma$.

\subsubsection{Método de Estimação das Caudas}

Considerando a variável aleatória $X$ com função de distribuição $F$, a partir das observações $x_{1}, x_{2}, \ldots, x_{N}$ independentes da v.a. $\mathrm{X}^{1}$, esse método consiste em analisar o comportamento assintótico de $F(x), x \in R$, quando $n \rightarrow \infty$, isto é, visa a estimação da cauda direita de $F^{2}$.

Considerando $\gamma \in R, \mu \in R$ e $\sigma>0$, define-se a função $G_{\gamma, \mu, \sigma}(x), x \in R$ da forma:

$$
G_{\gamma, \mu, \sigma}(x)=G_{\gamma}\left(\frac{x-\mu}{\sigma}\right), \quad x \in R .
$$

A propriedade (ii) do Teorema 1 implica que para $u$ suficientemente grande, $F(x), x \geq u$, aproxima-se de:

$$
P[X>u] G_{\gamma, \mu, \sigma}(x)+P[X \leq u], \quad x \geq u
$$

Esta aproximação é considerada como base para a estimação da cauda de $F$ e sugere o algoritmo de aproximação da cauda direita, chamado POT, descrito a seguir:

- Ordena-se de forma decrescente a amostra $x_{1}, x_{2}, \ldots, x_{N}$ e escolhe-se os $k$ maiores valores: $x_{N, k}, x_{N, k-1}, \ldots, x$ - Faz-se $u=x_{N, k}$ e usa-se estes $k$ valores para obter as estimativas de $\gamma$ e $\sigma(u)$ e estima-se $P[X>u]$ por $1-F(u)$ e $P[X<u]$ por $F(u)$.

Relativamente ao método POT, destaca-se a seguinte terminologia:

- $u$ limiar acima do qual os valores de $x$ são considerados integrantes da cauda.

\footnotetext{
${ }^{1} \mathrm{~A}$ suposição de independência pode ser relaxada

${ }^{2}$ Para a análise da cauda esquerda, na prática, inverte-se os sinais das observações da amostra
} 
- $\gamma$ é o índice caudal.

- $\mu$ é o parâmetro de localização.

- $\sigma$ é o parâmetro de escala.

- $k$ é o número de extremos utilizados na estimativa dos parâmetros.

\subsection{Procedimento Experimental}

A $1^{\text {a }}$ etapa para a realização deste ensaio foi a construção das séries de retornos dos ativos em estudo, correspondentes a níveis de suas respectivas estimativas de volatilidade, isto é, as séries são formadas agregando-se à inicial observações correspondentes à estimativas de volatilidade mais altas para a formação da segunda série, e assim sucessivamente até se formar a série completa. Optamos por uma escolha"empírica, de tal forma que as séries assim obtidas pudessem ser representativas da amostra total e possibilitassem a nossa análise quanto ao comportamento dos retornos dos ativos conforme suas estimativas de volatilidade são mais altas. A Tabela 5.1 exibe o procedimento adotado para a obtenção dos níveis de estimativas de volatilidade formando, dessa forma, as faixas para todos os ativos.

Tabela 5.1: Procedimento adotado para obtenção das séries de retornos dos ativos correspondentes a níveis de estimativas de volatilidade

\begin{tabular}{|l|l|}
\hline Faixas & Critério adotado \\
\hline \hline Faixa 1 & Retornos correspondentes a estimativas de $[0-0.2]$ da média de V.E. \\
\hline Faixa 2 & Retornos correspondentes a estimativas de $[0-0.5]$ da média de V.E. \\
\hline Faixa 3 & Retornos correspondentes a estimativas de $[0-1.0]$ da média de V.E. \\
\hline Faixa 4 & Retornos correspondentes a estimativas de $[0-1.5]$ da média de V.E. \\
\hline Faixa 5 & Retornos correspondentes a estimativas de $[0-2.0]$ da média de V.E. \\
\hline Faixa 6 & Retornos correspondentes a estimativas de $[0-1.0]$ do máximo de V.E. \\
\hline \hline
\end{tabular}

Em que pese, ser consenso na literatura que as estatísticas descritivas têm menor importância quando se estuda o comportamento das caudas, por serem suas medidas indicadoras do comportamento da maioria das observações e não das mais raras, elaboramos a análise descritiva das séries obtidas para uma exploração inicial dos dados, em especial quanto à medida da curtose de cada uma, visto que ainda paira uma certa idéia de que a mesma seria uma medida de peso das caudas, sendo comum a afirmação de que se seu valor for maior do que a curtose de uma distribuição Normal, as caudas das distribuições em análise seriam grossas.

Nesse sentido, por nosso objetivo ser especificamente a análise das caudas, enfatizamos muito mais os resultados obtidos das parametrizações das caudas por meio da Teoria de Valores Extremos, os quais foram analisados através de um dos softwares dedicados a valores extremos, o Xtremes 3.0. 


\subsubsection{Estimação dos Parâmetros}

Para a estimação dos parâmetros $\gamma$ e $\sigma(u)$ optamos pelo método de Máxima Verossimilhança (Maximum Likelihood Estimation - MLE), também descrito em Embrechts et al. A opção por esse método deve-se pelo explicado em nossa literatura de referência, de que ele funciona bem e suas propriedades de consistência e eficiência assintótica são válidas e de que possui mais estabilidade em suas estimativas do parâmetro $\gamma$ para variações do número $k$ de extremos considerados do que outros estimadores disponíveis no Xtremes.

\section{O número $k$-ótimo de estatísticas de ordem - extremos}

A determinação do número de extremos é um fator que pode comprometer as estimações dos parâmetros, visto que:

- Se $k$ é pequeno o método MLE usa usa uma quantidade de extremos que deixa o resultado estatisticamente instável e, ainda, pequena mudança no valor da observação altera significativamente o resultado.

- Se $k$ muito grande o método MLE usa alguns valores da amostra que não informam sobre o comportamento da cauda, afetando, dessa forma, o resultado da estimativa.

Visando contornar as dificuldades apontadas, o procedimento adotado em nosso trabalho foi o seguinte:

- Inicialmente utilizamos um método de seleção automática fornecido pelo Xtremes e, adicionalmente, construímos o Gráfico de Hill, o qual é um gráfico da estimativa do parâmetro $\hat{\gamma}$ em função de $k$, para verificar visualmente, a partir de que momento as flutuações fortes de $\hat{\gamma}$ para variações de $k$ deixam de existir, de tal forma que se possa identificar os valores das estimativas de $\hat{\gamma}$ que tendem a se estabilizar em torno do valor verdadeiro de $\gamma$. Ressaltamos que a utilização do Gráfico de Hill pressupõe a existência de estabilidade na estimativa, o que pode não ocorrer. Ressaltamos que nas séries construídas neste estudo, tal fato, juntamente com pequeno número de observações em algumas, não nos permitiu fazer conclusão a respeito de suas caudas.

\section{Análise da Adequação do Modelo}

Para a análise do ajuste do modelo POT utilizamos ferramentas disponíveis do software Xtremes. Essa ferramentas visuais são os gráficos da função da média e da mediana dos excessos, função de distribuição acumulada e QQ-plot. Essas técnicas são consideradas as melhores entre as disponíveis, como dito em Embrechets et al. Essas funções possibilitam verificar se $F$, a função de distribuição que estima a cauda à direita de $u$, utilizando os $k$ maiores valores $x_{N, k}, \ldots, x_{N, 1}$, é bem aproximada por $H_{\gamma}$, a distribuição de Pareto generalizada. Essas funções, média e mediana dos excessos, devem-se comportar como uma função linear em $u$, caso aconteça a referida proximidade. Na literaturada usada em nosso trabalho, os autores explicam que, devido serem esparsos os dados para o cálculo de $u$, os gráficos resultantes da média são muito sensíveis à mudanças nos dados em direção ao extremo da amostra e sugerem o uso de versões mais fortes, como o gráfico da mediana 
dos excessos. Adotamos essa sugestão em nossa análise.

\section{Testes do sinal de $\gamma$}

Testamos a hipótese de $\gamma=0$ por dois métodos, descritos em Reis e Thomas - "...", disponíveis no software Xtremes, os quais são os seguintes:

- teste de Hashofer-Wang.

- índice de verossimilhança com correção de Bartlett.

Esses testes forneceram um p-valor para a hipótese testada de $\gamma=0$ para as caudas das séries construídas neste estudo.

Por termos as séries formadas neste trabalho com números relativamente pequenos para fazer inferências por meio da TVE, para concluirmos quanto à forma das caudas analisadas (cauda grossa $-\gamma>0$ ou cauda fina $-\gamma<0$ ) levamos em conta apenas as situações em que os p-valor dos testes adotados fossem compatíveis entre si para níveis $\leq 0.01$ ou $\geq 0.1$, isto é, aceitamos $\gamma=0$ quando os p-valores estimados foram maiores que $0.1 \mathrm{e}$, rejeitamos a hipótese $\gamma=0$ quando os p-valores estimados foram menores que 0.01 .

\subsection{Resultados da Análise}

\subsubsection{Ativo Ibovespa}

A Figura 5.1 exibe o box-plot das séries de retornos correspondentes às faixas de estimativas de volatilidade obtidas pelo modelo de V.E. (Volatilidade Estocástica). A Tabela 5.2 mostra as estatísticas descritivas das séries de retornos obtidas em todas as faixas no período em estudo. A Tabela 5.3 apresenta as estimativas dos parâmetros da análise pela TVE para as duas caudas de todas as séries em questão (exceto as séries correspondentes às faixas 1 e 2 por não possuírem observações suficientes), obtidas conforme descrito na Seç̧ão 5.2. Esta tabela também apresenta os resultados de dois testes para a hipótese de $\gamma=0$ (Hashofer Wang - H.W. e Índice de Verossimilhança - LR-BC). As conclusões extraídas constam da Secção 5.4. Inserimos, ao final desta Seç̧ão, os gráficos de Hill do parâmetro $\gamma$ para as caudas direita e esquerda das séries construídas deste ativo para exemplificação (Figuras 5.2 a 5.9). Esses gráficos foram utilizados, juntamente com a seleção automática do software Xtremes 3.0, para a obtenção do número de extremos ótimo (k) utilizados para a parametrização das caudas. 
Tabela 5.2: ativo Ibovespa - Estatística Descritiva dos retornos das séries obtidas por faixas correspondentes às estimativas de volatilidade (V.E.) - ativo Ibovespa

\begin{tabular}{|l|l|l|l|l|l|l|}
\hline \multicolumn{7}{|c|}{ Estatística Descritiva } \\
\hline & Faixa 1 & Faixa 2 & Faixa 3 & Faixa 4 & Faixa 5 & Faixa 6 \\
\hline \hline $\mathrm{N}^{\circ}$ Observações & 0 & 113 & 1130 & 1439 & 1474 & 1594 \\
\hline Mínimo & - & -3.36 & -9.68 & -9.68 & -9.68 & -17.28 \\
\hline Mediana & - & 0.09 & 0.03 & 0.02 & -0.00 & -0.03 \\
\hline Média & - & 0.15 & 0.03 & 0.03 & 0.01 & 0.00 \\
\hline Máximo & - & 3.31 & 7.29 & 8.35 & 8.35 & 28.77 \\
\hline D.padrão & - & 1.19 & 1.78 & 1.96 & 2.00 & 2.47 \\
\hline Assimetria & - & 0.00 & -0.29 & -0.19 & -0.17 & 0.84 \\
\hline Curtose & - & 3.57 & 4.46 & 3.99 & 3.95 & 18.52 \\
\hline \hline Jarque-Bera & - & 1.54 & 116.41 & 67.84 & 62.19 & 16185.49 \\
Probabilidade & - & 0.47 & 0.00 & 0.00 & 0.00 & 0.00 \\
\hline \hline
\end{tabular}

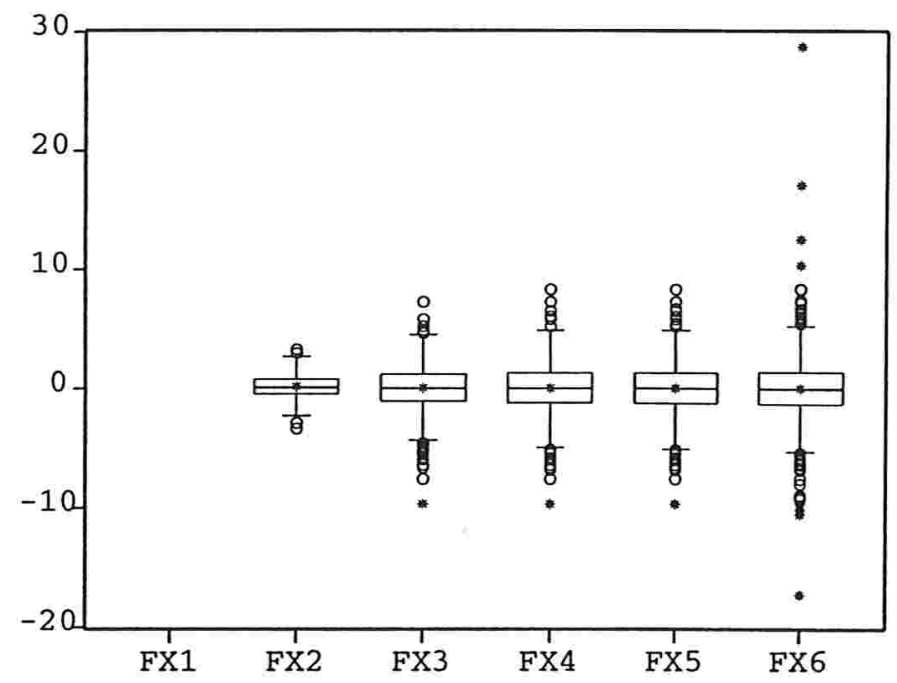

Figura 5.1: Boxplot das séries de retornos do ativo Ibovespa por faixas de estimativas de volatilidade crescentes - V.E. 
Tabela 5.3: ativo Ibovespa - Resultados da parametrização das caudas dos retornos de cada faixa por GPD

\begin{tabular}{|c|c|c|c|c|c|c|c|}
\hline \multirow[t]{2}{*}{ Cauda } & \multirow[t]{2}{*}{ Retornos } & \multirow[t]{2}{*}{$k$} & \multicolumn{3}{|c|}{ Parâmetros da GPD } & \multicolumn{2}{|c|}{ P-valor para a hip. $\gamma=0$} \\
\hline & & & $\gamma$ & $\mu$ & $\sigma$ & H.W. & LR BC \\
\hline \multirow[t]{6}{*}{ Direita } & Faixa 1 & - & - & - & - & - & - \\
\hline & Faixa 2 & - & - & - & - & - & - \\
\hline & Faixa 3 & 174 & -0.048 & -0.054 & 1.027 & 0.475 & 0.549 \\
\hline & Faixa 4 & 259 & -0.041 & -0.107 & 1.137 & 0.455 & 0.521 \\
\hline & Faixa 5 & 250 & -0.031 & -0.115 & 1.139 & 0.608 & 0.657 \\
\hline & Faixa 6 & 190 & 0.293 & 0.719 & 0.561 & 0.001 & 0.001 \\
\hline \multirow[t]{6}{*}{ Esquerda } & Faixa 1 & - & - & - & - & - & - \\
\hline & Faixa 2 & - & - & - & - & - & - \\
\hline & Faixa 3 & 200 & 0.043 & -02.79 & 0.981 & 0.471 & 0.476 \\
\hline & Faixa 4 & 189 & -0.027 & -0.054 & 1.027 & 0.714 & 0.767 \\
\hline & Faixa 5 & 421 & -0.055 & -0.735 & 1.471 & 0.246 & 0.271 \\
\hline & Faixa 6 & 298 & 0.064 & -0.682 & 1.353 & 0.135 & 0.186 \\
\hline
\end{tabular}




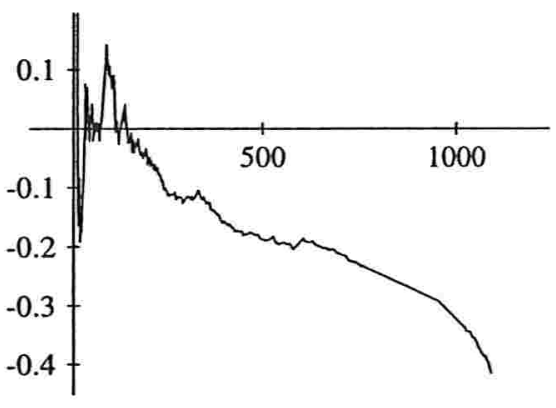

Figura 5.2: Gráfico de Hill de retornos do Ibovespa - Faixa 3 (cauda direita). Estimativas de $\gamma \times{ }^{\prime \prime} \mathrm{k}-\mathrm{n}^{\circ}$ de extremos POT"

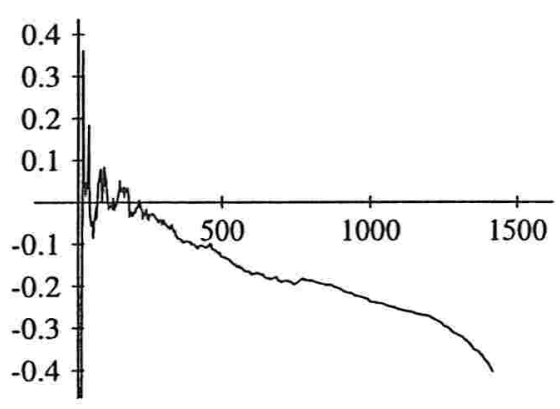

Figura 5.4: Gráfico de Hill de retornos do Ibovespa - Faixa 5 (cauda direita). Estimativas de $\gamma \mathrm{x} " \mathrm{k}-\mathrm{n}^{\circ}$ de extremos POT"

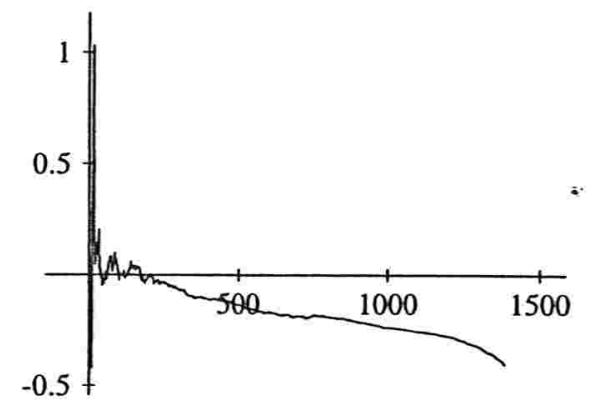

Figura 5.3: Gráfico de Hill de retornos do Ibovespa - Faixa 4 (cauda direita). Estimativas de $\gamma \mathrm{x} " \mathrm{k}-\mathrm{n}^{\mathrm{o}}$ de extremos POT"

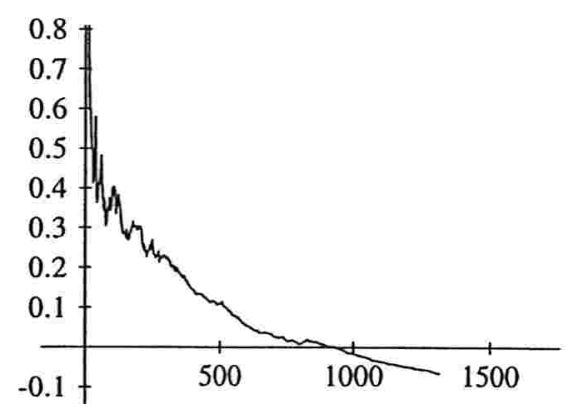

Figura 5.5: Gráfico de Hill de retornos do Ibovespa - Faixa 6 (cauda direita). Estimativas de $\gamma \mathrm{x} " \mathrm{k}-\mathrm{n}^{\mathrm{o}}$ de extremos POT" 


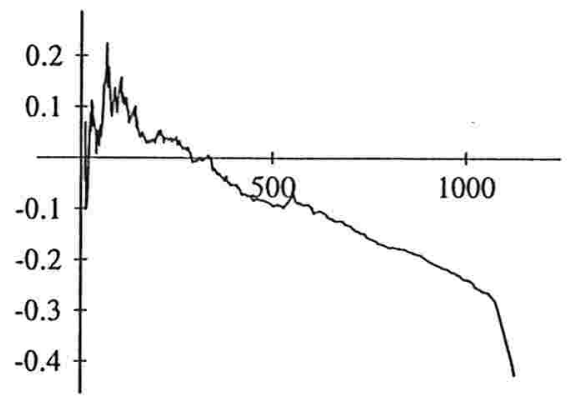

Figura 5.6: Gráfico de Hill de retornos do Ibovespa - Faixa 3 (cauda esquerda). Estimativas de $\gamma \mathrm{x}$ " $\mathrm{k}$ $\mathrm{n}^{\circ}$ de extremos POT"

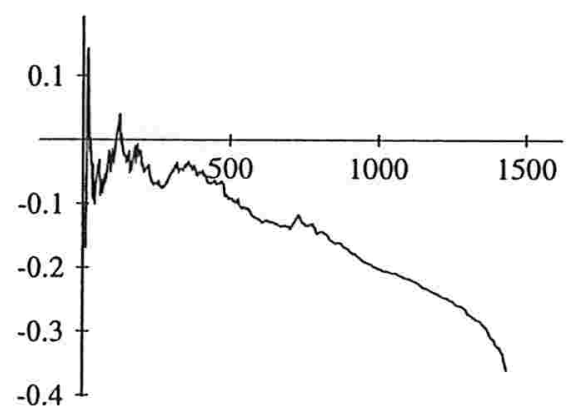

Figura 5.8: Gráfico de Hill de retornos do Ibovespa - Faixa 5 (cauda esquerda). Estimativas de $\gamma \mathrm{x}$ "k $\mathrm{n}^{\circ}$ de extremos POT"

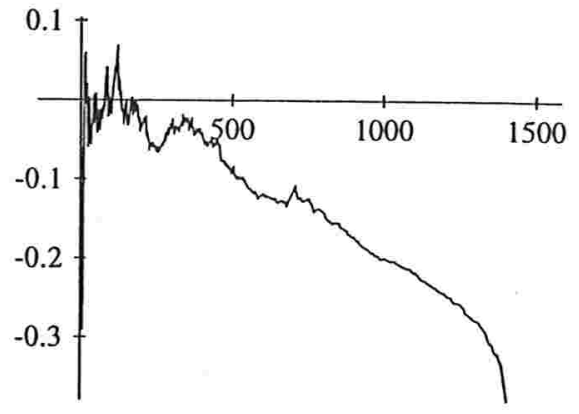

Figura 5.7: Gráfico de Hill de retornos do Ibovespa - Faixa 4 (cauda esquerda). Estimativas de $\gamma \mathrm{x} " \mathrm{k}$ $n^{\circ}$ de extremos POT"

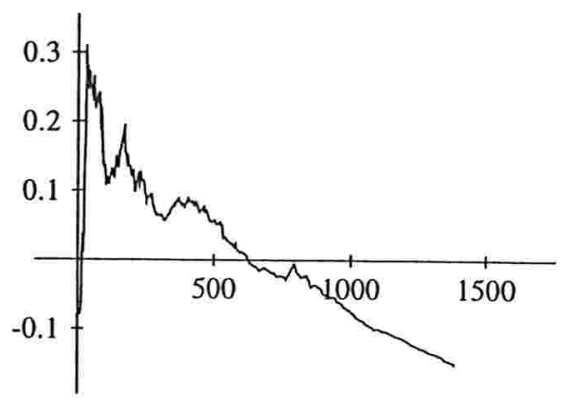

Figura 5.9: Gráfico de Hill de retornos do Ibovespa - Faixa 6 (cauda esquerda). Estimativas de $\gamma \mathrm{x}$ " $\mathrm{k}$ $\mathrm{n}^{\circ}$ de extremos POT" 


\subsubsection{Ativo Dólar}

A Figura 5.10 exibe o box-plot das séries de retornos correspondentes à faixas de estimativas de volatilidade obtidas pelo modelo de V.E. (Volatilidade Estocástica). A Tabela 5.4 exibe as estatísticas descritivas das séries de retornos obtidas em todas as faixas no período em estudo. A Tabela 5.5 apresenta as estimativas dos parâmetros da análise pela TVE para as duas caudas de todas as séries em questão (exceto a série correspondente à faixa 1 por não possuir observações suficientes), obtidas conforme descrito na Secção 5.2, juntamente com as estimativas dos p-valores dos testes para a hipótese de $\gamma=0$ ). As conclusões extraídas constam da Secção 5.4. Omitimos os gráficos de Hill do parâmetro $\gamma$ para as caudas das séries construídas deste ativo nesta Secção. Apresentamos em anexo.

Tabela 5.4: ativo Dólar - Estatística Descritiva dos retornos das séries obtidas por faixas correspondentes às estimativas de volatilidade (V.E.)

\begin{tabular}{|l|l|l|l|l|l|l|}
\hline \multicolumn{7}{|c|}{ Estatística Descritiva } \\
\hline & Faixa 1 & Faixa 2 & Faixa 3 & Faixa 4 & Faixa 5 & Faixa 6 \\
\hline \hline $\mathrm{N}^{\circ}$ Observações & 438 & 846 & 1186 & 1305 & 1398 & 1594 \\
\hline Mínimo & -1.00 & -1.94 & -2.37 & -3.09 & -3.37 & -9.42 \\
\hline Mediana & -0.03 & -0.03 & -0.03 & -0.03 & -0.03 & -0.03 \\
\hline Média & -0.02 & -0.03 & -0.02 & -0.02 & -0.03 & 0.00 \\
\hline Máximo & 0.92 & 1.49 & 8.47 & 8.47 & 8.47 & 10.47 \\
\hline D.padrão & 0.18 & 0.37 & 0.59 & 0.64 & 0.70 & 1.07 \\
\hline Assimetria & -0.34 & -0.09 & 2.59 & 1.75 & 1.05 & 0.34 \\
\hline Curtose & 9.87 & 5.08 & 40.82 & 28.41 & 20.12 & 21.31 \\
\hline \hline Jarque-Bera & 870.13 & 153.81 & 72020.29 & 35759.68 & 17339.96 & 22288.40 \\
Probabilidade & 0.00 & 0.00 & 0.00 & 0.00 & 0.00 & 0.00 \\
\hline \hline
\end{tabular}




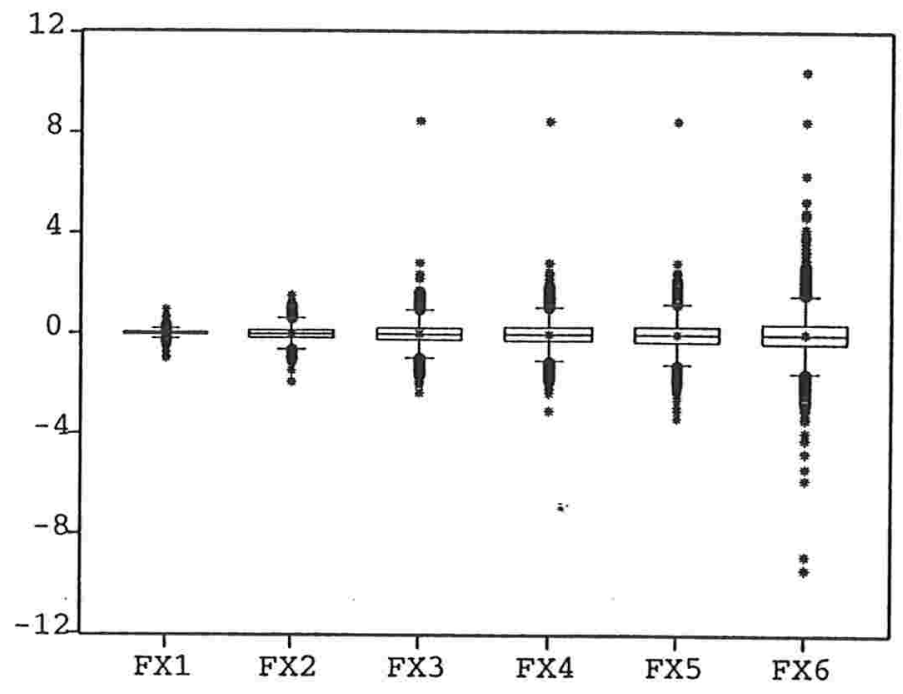

Figura 5.10: Boxplot das séries de retornos do ativo Dólar por faixas de estimativas de volatilidade crescentes - V.E.

Tabela 5.5: ativo Dólar - Resultados da parametrização das caudas dos retornos de cada faixa por GPD

\begin{tabular}{|l|l|l|l|l|l|l|l|}
\hline Cauda & Retornos & $k$ & \multicolumn{2}{|l|}{ Parâmetros da GPD } & \multicolumn{2}{l|}{ P-valor para a hip. $\gamma=0$} \\
\cline { 4 - 8 } & & & $\gamma$ & $\mu$ & $\sigma$ & H.W. & LR BC \\
\hline \hline \multirow{5}{*}{ Direita } & Faixa 1 & 101 & 0.059 & -0.153 & 0.124 & 0.550 & 0.509 \\
\cline { 2 - 8 } & Faixa 2 & 16 & -0.158 & -0.362 & 0.408 & 0.72 & 1 \\
\cline { 2 - 8 } & Faixa 3 & 31 & 0.564 & 0.700 & 0.032 & 0.001 & 0.000 \\
\cline { 2 - 8 } & Faixa 4 & 40 & 0.434 & 0.541 & 0.069 & 0.001 & 0.000 \\
\cline { 2 - 7 } & Faixa 5 & 79 & 0.308 & 0.332 & 0.140 & 0.000 & 0.000 \\
\cline { 2 - 7 } & Faixa 6 & 78 & 0.168 & -1.222 & 0.639 & 0.137 & 0.114 \\
\hline \hline Esquerda & Faixa 1 & 20 & -0.084 & -0.436 & 0.278 & 0.906 & 1 \\
\cline { 2 - 7 } & Faixa 2 & 75 & -0.032 & -0.064 & 0.260 & 0.754 & 0.857 \\
\cline { 2 - 7 } & Faixa 3 & 20 & -0.081 & -0.252 & 0.444 & 0.293 & 0.316 \\
\cline { 2 - 7 } & Faixa 4 & 40 & -0.099 & -0.665 & 0.635 & 0.481 & 0.623 \\
\cline { 2 - 7 } & Faixa 5 & 80 & -0.087 & -0.272 & 0.737 & 0.579 & 0.598 \\
\cline { 2 - 7 } & Faixa 6 & 184 & 0.195 & -0.212 & 0.432 & 0.000 & 0.000 \\
\hline \hline
\end{tabular}




\subsubsection{Ativo Taxa Pré Juros}

A Figura 5.11 exibe o box-plot das séries de retornos correspondentes à faixas de estimativas de volatilidade obtidas pelo modelo de V.E. (Volatilidade Estocástica). A Tabela 5.6 exibe as estatísticas descritivas das séries de retornos obtidas em todas as faixas no período em estudo. A Tabela 5.7 apresenta as estimativas dos parâmetros da análise pela TVE para as duas caudas de todas as séries em questão (exceto a série correspondente à faixa 1 por não possuir observações suficientes), obtidas conforme descrito na Seç̧ão 5.2, juntamente com as estimativas dos p-valores dos testes para a hipótese de $\gamma=0$ ). As conclusões extraídas constam da Secção 5.4. Omitimos os gráficos de Hill do parâmetro $\gamma$ para as caudas das séries construídas deste ativo nesta Seç̧ão. Apresentamos em anexo.

Tabela 5.6: ativo Taxa Pré de Juros - Estatística Descritiva dos retornos das séries obtidas por faixas correspondentes às estimativas de volatilidade (V.E.)

\begin{tabular}{|l|l|l|l|l|l|l|}
\hline \multicolumn{7}{|c|}{ Estatística Descritiva } \\
\hline & Faixa 1 & Faixa 2 & Faixa 3 & Faixa 4 & Faixa 5 & Faixa 6 \\
\hline \hline$N^{\circ}$ Observações & 181 & 669 & 1171 & 1329 & 1401 & 1594 \\
\hline Mínimo & -2.25 & -5.01 & -7.38 & -7.38 & -8.41 & -25.10 \\
\hline Mediana & -0.07 & -0.08 & -0.11 & -0.09 & -0.06 & -0.06 \\
\hline Média & -0.06 & -011 & -0.12 & -0.10 & -0.09 & 0,00 \\
\hline Máximo & 1.82 & 3.27 & 6.90 & 9.01 & 10.50 & 21.15 \\
\hline D.padrão & 0.58 & 0.93 & 1.36 & 1.54 & 1.66 & 2.45 \\
\hline Assimetria & 0.28 & -0.17 & -0.08 & 0.22 & 0.31 & 0.05 \\
\hline Curtose & 4.58 & 4.47 & 6.22 & 6.27 & 7.01 & 18.82 \\
\hline \hline Jarque-Bera & 21.16 & 63.50 & 509.25 & 603.51 & 959.74 & 16613.93 \\
Probabilidade & 0.00 & 0.00 & 0.00 & 0.00 & 0.00 & 0.00 \\
\hline \hline
\end{tabular}




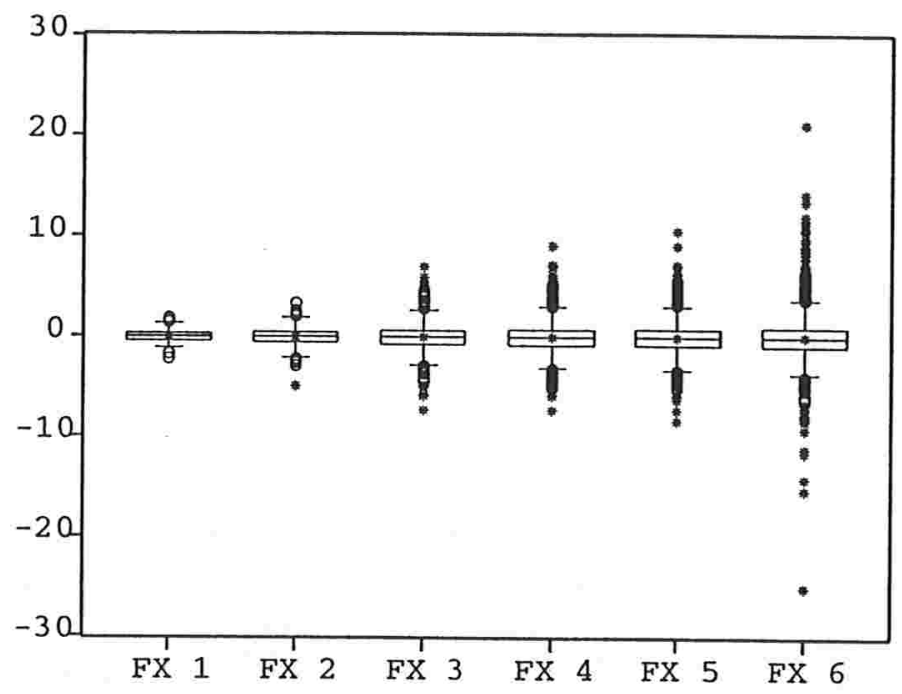

Figura 5.11: Boxplot das séries de retornos do ativo Taxa Pré Juros por faixas de estimativas de volatilidade crescentes - V.E.

Tabela 5.7: ativo Taxa Pré de Juros - Resultados da parametrização das caudas dos retornos de cada faixa por GPD

\begin{tabular}{|l|l|l|l|l|l|l|l|}
\hline Cauda & Retornos & $k$ & \multicolumn{2}{|l|}{ Parâmetros da GPD } & \multicolumn{2}{l|}{ P-valor para a hip. $\gamma=0$} \\
\cline { 4 - 8 } & & & $\gamma$ & $\mu$ & $\sigma$ & H.W. & LR BC \\
\hline \hline \multirow{5}{*}{ Direita } & Faixa 1 & & & & & & \\
\cline { 2 - 8 } & Faixa 2 & 90 & -0.161 & -0619 & 0.867 & 0.120 & 0.168 \\
\cline { 2 - 8 } & Faixa 3 & 250 & 0.007 & -0.705 & 0.917 & 0.877 & 0.878 \\
\cline { 2 - 8 } & Faixa 4 & 280 & 0.0524 & -0.702 & 0.951 & 0.315 & 0.325 \\
\cline { 2 - 8 } & Faixa 5 & 260 & 0.076 & -0.747 & 0.993 & 0.143 & 0.148 \\
\cline { 2 - 8 } & Faixa 6 & 190 & 0.247 & -0.740 & 0.969 & 0.006 & 0.001 \\
\hline \hline \multirow{5}{*}{ Esquerda a a } & Faixa 1 & & & & & & \\
\cline { 2 - 8 } & Faixa 2 & 150 & -0.027 & -0.223 & 0.651 & 0.691 & 0.766 \\
\cline { 2 - 7 } & Faixa 3 & 190 & 0.066 & -0.301 & 0.779 & 0.288 & 0.270 \\
\cline { 2 - 7 } & Faixa 4 & 185 & 0.027 & -0.425 & 0.951 & 0.723 & 0.669 \\
\cline { 2 - 7 } & Faixa 5 & 190 & 0.036 & -0.51 & 1.013 & 0.611 & 0.561 \\
\cline { 2 - 7 } & Faixa 6 & 210 & 0.249 & -0.345 & 0.810 & 0.00 & 0.00 \\
\hline \hline
\end{tabular}




\subsubsection{Ativo Cupom Cambial}

A Figura 5.12 exibe o box-plot das séries de retornos correspondentes à faixas de estimativas de volatilidade obtidas pelo modelo de V.E. (Volatilidade Estocástica). A Tabela 5.8 exibe as estatísticas descritivas das séries de retornos obtidas em todas as faixas no período em estudo. A Tabela 5.9 apresenta as estimativas dos parâmetros da análise pela TVE para as duas caudas de todas as séries em questão (exceto a série correspondente à faixa 1 por não possuir observações suficientes), obtidas conforme descrito na Secção 5.2, juntamente com as estimativas dos p-valores dos testes para a hipótese de $\gamma=0$ ). As conclusões extraídas constam da Seç̧ão 5.4. Omitimos os gráficos de Hill do parâmetro $\gamma$ para as caudas das séries construídas deste ativo nesta Secção. Apresentamos em anexo.

Tabela 5.8: ativo Taxa Cupom Cambial - Estatística Descritiva dos retornos das séries obtidas por faixas correspondentes às estimativas de volatilidade (V.E.)

\begin{tabular}{|l|l|l|l|l|l|l|}
\hline \multicolumn{7}{|c|}{ Estatística Descritiva } \\
\hline & Faixa 1 & Faixa 2 & Faixa 3 & Faixa 4 & Faixa 5 & Faixa 6 \\
\hline \hline $\mathrm{N}^{\mathbf{0}}$ Observações & 335 & 782 & 960 & 1142 & 1339 & 1594 \\
\hline Mínimo & -15.64 & -30.29 & -30.29 & -50.64 & -65.31 & -101.15 \\
\hline Mediana & 0.01 & -0.02 & 0.01 & 0.06 & 0.07 & 0.06 \\
\hline Média & 0.01 & -0.17 & -0.08 & 0.06 & 0.01 & 0.00 \\
\hline Máximo & 13.83 & 38.34 & 45.38 & 67.53 & 67.53 & 102.47 \\
\hline D.padrão & 2.81 & 6.83 & 8.23 & 10.24 & 12.71 & 16.69 \\
\hline Assimetria & 0.03 & 0.31 & 0.39 & 0.12 & -0.05 & -0.07 \\
\hline Curtose & 10.87 & 7.47 & 6.52 & 7.82 & 6.59 & 7.67 \\
\hline \hline Jarque-Bera & 864.59 & 664.44 & 520.48 & 1110.56 & 720.43 & 1452.28 \\
Probabilidade & 0.00 & 0.00 & 0.00 & 0.00 & 0.00 & 0.00 \\
\hline \hline
\end{tabular}




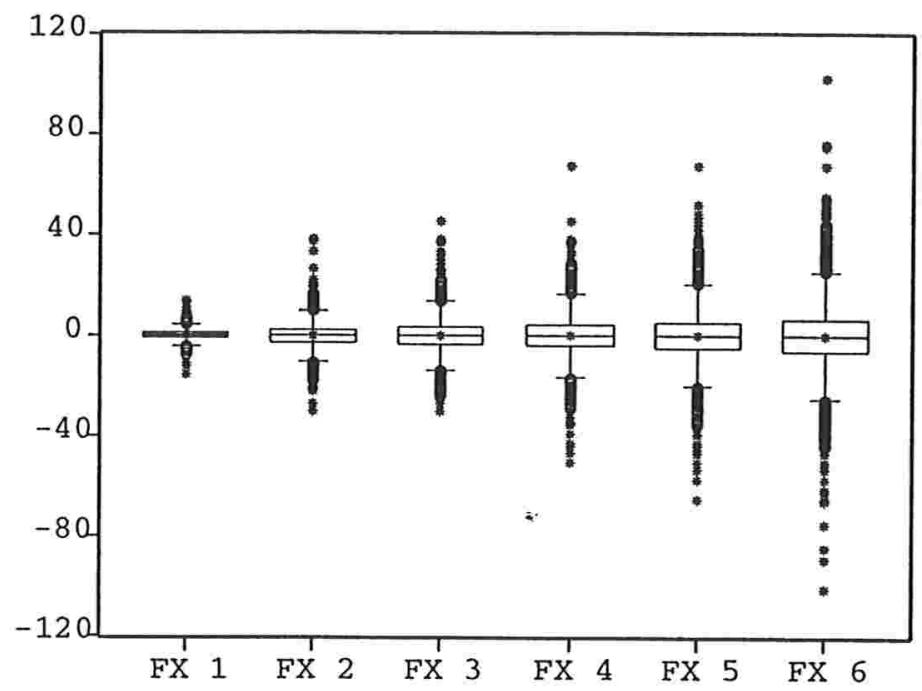

Figura 5.12: Boxplot das séries de retornos do ativo Taxa Cupom Cambial por faixas de estimativas de volatilidade crescentes - V.E.

Tabela 5.9: ativo Taxa Cupom Cambial - Resultados da parametrização das caudas dos retornos de cada faixa por GPD

\begin{tabular}{|c|c|c|c|c|c|c|c|}
\hline \multirow[t]{2}{*}{ Cauda } & \multirow[t]{2}{*}{ Retornos } & \multirow[t]{2}{*}{$k$} & \multicolumn{3}{|c|}{ Parâmetros da GPD } & \multicolumn{2}{|c|}{ P-valor para a hip. $\gamma=0$} \\
\hline & & & $\gamma$ & $\mu$ & $\sigma$ & H.W. & LR BC \\
\hline \multirow[t]{6}{*}{ Direita } & Faixa 1 & & & & & & \\
\hline & Faixa 2 & 160 & 0.058 & -3.955 & 4.541 & 0.382 & 0.393 \\
\hline & Faixa 3 & 135 & 0.121 & -2.097 & 4.223 & 0.166 & 0.135 \\
\hline & Faixa 4 & 160 & 0.119 & -3.346 & 5.410 & 0.151 & 0.112 \\
\hline & Faixa 5 & 180 & 0.040 & -6.421 & 8.462 & 0.696 & 0.608 \\
\hline & Faixa 6 & 307 & 0.008 & -11.414 & 12.743 & 0.873 & 0.861 \\
\hline \multirow[t]{6}{*}{ Esquerda } & Faixa 1 & & & & & & \\
\hline & Faixa 2 & 130 & -0.114 & -6.87 & 7.316 & 0.319 & 0.297 \\
\hline & Faixa 3 & 75 & -0.107 & -15.521 & 15.339 & 0.127 & 0.131 \\
\hline & Faixa 4 & 190 & 0.029 & -6.227 & 7.256 & 0.668 & 0.627 \\
\hline & Faixa 5 & 103 & -0.105 & -19.015 & 15.604 & 0.392 & 0.401 \\
\hline & Faixa 6 & 180 & 0.032 & -10.369 & 11.867 & 0.563 & 0.558 \\
\hline
\end{tabular}




\subsection{Conclusão}

Neste ensaio, como explicitado na Introdução deste trabalho, nós visamos analisar o comportamento das caudas das séries de retornos dos ativos à medida em que suas estimativas de volatilidade são mais altas, isto é, propomo-nos a analisar se as caudas das distribuições dos retornos de determinado ativo são as mesmas em todas as faixas construídas como já explicado na Secção 5.2. Adicionalmente, verificamos se para cada série, as caudas direita e esquerda dos retornos eram de tipos diferentes e verificamos se os dados das estatísticas descritivas, em especial a medida de curtose, eram indicadores dos mesmos resultados.

Em função dos resultados exibidos na Secção 5.3, apresentamos as nossas conclusões a respeito. As estatísticas descritivas para todos os ativos, em uma análise inicial, indicavam que as caudas dos retornos de todos os ativos eram pesadas em todas as suas faixas. Entretanto, o estudo da estimação das caudas nos levou à conclusões diferentes. Assim, apresentamos os resultados considerados consistentes de acordo com o critério adotado no ensaio, os quais estão exibidos nas Tabelas 5.10, 5.11, 5.12 e 5.13, relativamente aos ativos Ibovespa, Dólar, Taxa Pré de Juros e Taxa Cupom Cambial, respectivamente.

Tabela 5.10: ativo Ibovespa - Formas das caudas em cada faixa de acordo com as estimativas de $\gamma$ consideradas aceitas

\begin{tabular}{|l|l|c|c|c|}
\hline Ativo: Ibovespa & \multicolumn{3}{|c|}{} \\
\hline Cauda & Retornos & $\begin{array}{c}\text { Tipo Beta } \\
\gamma<0\end{array}$ & $\begin{array}{c}\text { Tipo Exponencial } \\
\gamma=0\end{array}$ & $\begin{array}{c}\text { Tipo Pareto } \\
\gamma>0\end{array}$ \\
\hline \multirow{4}{*}{ Direita } & Faixa 1 & - & - & - \\
\cline { 2 - 5 } & Faixa 2 & - & - & - \\
\cline { 2 - 5 } & Faixa 3 & & $\mathrm{X}$ & \\
\cline { 2 - 5 } & Faixa 4 & & $\mathrm{X}$ & \\
\cline { 2 - 5 } & Faixa 5 & & $\mathrm{X}$ & $\mathrm{X}$ \\
\cline { 2 - 5 } & Faixa 6 & & & - \\
\hline \hline \multirow{5}{*}{ Esquerda } & Faixa 1 & - & - & \\
\cline { 2 - 5 } & Faixa 2 & - & - & \\
\cline { 2 - 5 } & Faixa 3 & & $\mathrm{X}$ & \\
\cline { 2 - 5 } & Faixa 4 & & $\mathrm{X}$ & \\
\cline { 2 - 5 } & Faixa 5 & & $\mathrm{X}$ & \\
\cline { 2 - 5 } & Faixa 6 & & $\mathrm{X}$ & \\
\hline
\end{tabular}

Quanto aos tipos de caudas observamos o seguinte:

- Ibovespa As estimativas consistentes de $\gamma$ indicaram caudas do tipo Exponencial em todas as faixas para a cauda esquerda, enquanto que para a cauda direita, foram indicativas de cauda tipo exponencial para as faixas 3, 4 e 5 e indicadora de cauda pesada, do tipo Pareto, para a faixa 6 , composta pela agregação de retornos correspondentes às mais altas estimativas de volatilidade.

- Dólar As estimativas de $\gamma$ indicaram comportamentos diferentes no que se refere às 
Tabela 5.11: ativo Dólar - Formas das caudas em cada faixa de acordo com as estimativas de $\gamma$ consideradas aceitas

\begin{tabular}{|c|c|c|c|c|}
\hline \multicolumn{5}{|c|}{ Ativo: Dólar } \\
\hline Cauda & Retornos & $\begin{array}{l}\text { Tipo Beta } \\
\gamma<0\end{array}$ & $\begin{array}{c}\text { Tipo Exponencial } \\
\gamma=0\end{array}$ & $\begin{array}{c}\text { Tipo Pareto } \\
\gamma>0\end{array}$ \\
\hline \multirow[t]{6}{*}{ Direita } & Faixa 1 & & $\mathrm{X}$ & \\
\hline & Faixa 2 & & $\mathrm{X}$ & \\
\hline & Faixa 3 & & & $\mathrm{X}$ \\
\hline & Faixa 4 & & & $\bar{X}$ \\
\hline & Faixa 5 & & & $\mathrm{X}$ \\
\hline & Faixa 6 & & $\mathrm{X}$ & \\
\hline \multirow[t]{6}{*}{ Esquerda } & Faixa 1 & & $\mathrm{X}$ & \\
\hline & Faixa 2 & & $\mathrm{X}$ & \\
\hline & Faixa 3 & & $\mathrm{X}$ & \\
\hline & Faixa 4 & & $\mathrm{X}$ & \\
\hline & Faixa 5 & & $\mathrm{X}$ & \\
\hline & Faixa 6 & & & $\mathrm{X}$ \\
\hline
\end{tabular}

caudas direita e esquerda, assim como também relativamente à mudança de faixas, sendo do tipo Pareto para as faixas 3, 4 e 5 e do tipo Exponencial para as faixas 1, 2 e 6 da cauda direita; já para a cauda esquerda houve indicativo de cauda do tipo Exponencial para as faixas de 1 a 5 e do tipo Pareto para a faixa 6 .

- Taxa Pré de Juros As estimativas consistentes de $\gamma$ indicaram comportamentos iguais para as duas caudas, tendo, entretanto, mudança relativamente às faixas, qual seja: do tipo Exponencial para as faixas 2 a 5 e do tipo Pareto para a faixas 6 de ambas as caudas.

- Taxa Cupom Cambial As estimativas consistentes de $\gamma$ indicaram que não houve mudança no comportamento das caudas por faixas e nem por caudas, sendo todas indicativas de caudas do tipo Exponencial, 
Tabela 5.12: ativo Taxa Pré de Juros - Formas das caudas em cada faixa de acordo com as estimativas de $\gamma$ consideradas aceitas

\begin{tabular}{|c|c|c|c|c|}
\hline \multicolumn{5}{|c|}{ Ativo: Taxa Pré de Juros } \\
\hline Cauda & Retornos & $\begin{array}{c}\text { Tipo Beta } \\
\gamma<0\end{array}$ & $\begin{array}{c}\text { Tipo Exponencial } \\
\gamma=0\end{array}$ & $\begin{array}{c}\text { Tipo Pareto } \\
\gamma>0\end{array}$ \\
\hline \multirow[t]{6}{*}{ Direita } & Faixa 1 & - & - & - \\
\hline & Faixa 2 & & $\mathrm{X}$ & \\
\hline & Faixa 3 & & $\mathrm{X}$ & \\
\hline & Faixa 4 & & $\mathrm{X}$ & \\
\hline & Faixa 5 & & $\mathrm{X}$ & \\
\hline & Faixa 6 & & & $\mathrm{X}$ \\
\hline \multirow[t]{6}{*}{ Esquerda } & Faixa 1 & - & - & - \\
\hline & Faixa 2 & & $\mathrm{X}$ & \\
\hline & Faixa 3 & & $\mathrm{X}$ & \\
\hline & Faixa 4 & & $\bar{X}$ & \\
\hline & Faixa 5 & & $\mathrm{X}$ & \\
\hline & Faixa 6 & & & $\mathrm{X}$ \\
\hline
\end{tabular}

Tabela 5.13: ativo Taxa Pré de Juros - Formas das caudas em cada faixa de acordo com as estimativas de $\gamma$ consideradas aceitas

\begin{tabular}{|l|l|c|c|c|}
\hline Ativo: Taxa Pré de Juros \\
\hline Cauda & Retornos & $\begin{array}{c}\text { Tipo Beta } \\
\gamma<0\end{array}$ & $\begin{array}{c}\text { Tipo Exponencial } \\
\gamma=0\end{array}$ & $\begin{array}{c}\text { Tipo Pareto } \\
\gamma>0\end{array}$ \\
\hline \multirow{4}{*}{ Direita } & Faixa 1 & - & - & - \\
\hline & Faixa 2 & & $\mathrm{X}$ & \\
\hline & Faixa 3 & & $\mathrm{X}$ & \\
\hline & Faixa 4 & & $\mathrm{X}$ & \\
\hline & Faixa 5 & & $\mathrm{X}$ & \\
\hline & Faixa 6 & & $\mathrm{X}$ & \\
\hline \hline \multirow{5}{*}{ Esquerda } & Faixa 1 & - & - & \\
\cline { 2 - 5 } & Faixa 2 & & $\mathrm{X}$ & \\
\hline & Faixa 3 & & $\mathrm{X}$ & \\
\hline & Faixa 4 & & $\mathrm{X}$ & \\
\hline & Faixa 5 & & $\mathrm{X}$ & \\
\hline & Faixa 6 & & $\mathrm{X}$ & \\
\hline
\end{tabular}




\section{Capítulo 6}

\section{Ensaio $\mathrm{n}^{\mathrm{O}} 2$ - Caso bivariado: Análise da Dependência entre Pares de Retornos de Ativos Correspondentes a Faixas de Volatilidade Crescentes}

Este ensaio tem dois objetivos: Verificar se a dependência entre pares de ativos aumenta ou diminui conforme suas estimativas de volatilidade são mais altas simultaneamente e Analisar se para cada série obtida de par de ativos a dependência de seus retornos simultâneos aumenta ou diminui relativamente a períodos em que crises ou euforia dos mercados financeiros são mais acentuadas.

Para tanto, fizemos uso do coeficiente implícito de dependência extremal, construído e descrito no trabalho de Adonírio Panzieri, Vladimir Belitsky, Paulo R. M. Rocha e Fernando P. A. Prado (2004), do qual apresentamos uma sinopse na Seç̧ão 6.1.

\subsection{Coeficiente Implícito de Dependência Extremal}

No trabalho em que citamos nos basear para a apresentação do coeficiente implícito de dependência extremal, tal coeficiente surge da proposta de se responder à questão colocada no seguinte problema:

"Dada a amostra $\left(x_{1}, y_{1}\right), \ldots,\left(x_{n}, y_{n}\right)$ de observações simultâneas de $n$ retornos diários de dois ativos, deduzir se a dependência entre os retornos desses ativos aumenta ou diminui quando as situações de crises ou de euforia dos mercados financeiros tornam-se mais extremas."

- Notações e definições preliminares adotadas.

São denotados pelas variáveis aleatórias $X$ e $Y$ os retornos diários dos ativos para os quais a questão acima é posta e referem-se a esses ativos como sendo "os ativos $X$ e $Y$ "; o abuso da notação por questão de brevidade. 
Para $p \in(0,1)$, introduz-se:

$$
Z_{p}=p X+(1-p) Y
$$

Das definições de $X$ e $Y, Z_{p}$ denota os retornos diários do portfolio composto dos ativos $X$ e $Y$ com peso $p$ e $1-p$, respectivamente.

Para a variável aleatória $X$, denota-se por $F_{X}$ a sua função de distribuição. Para um número arbitrário $\alpha \in(0,1)$, denota-se por $\operatorname{Var}_{\alpha}(X)$ o $\alpha$-quantil de $F_{X}$ chamado de Valor de risco a nível $\alpha$ do ativo $X$. No trabalho os autores assumem a amostra $\left(x_{1}, y_{1}\right), \ldots,\left(x_{n}, y_{n}\right)$ como sendo observações independentes de $(X, y)$ e consideram irrelevante a discussão das vantagens e desvantagens do $V$ ar como medida de risco.

O coeficiente implícito de dependência extremal surge da comparação entre as eštimativas de quantis elevados de $Z_{p}$ dado por dois métodos, quais sejam:

- o $1^{\circ}$ método utiliza essencialmente o fato de que $x_{j}$ e $y_{j}$ da amostra $\left(x_{1}, y_{1}\right), \ldots,\left(x_{n}, y_{n}\right)$ são observações simultâneas de $X$ e $Y$ para cada $j$. Esse fato assegura que para algum $p \in[0,1]$ define-se:

$$
Z_{1}(p):=p x_{1}+(1-p) y_{1}, \ldots, Z_{n}(p):=p x_{n}+(1-p) y_{n}
$$

Então pode-se considerar a sequência $Z_{1}(p), \ldots, Z_{n}(p)$ como uma amostra de observações de $Z_{p}$. Esse $1^{\circ}$ método estima $\operatorname{Var}\left(Z_{p}\right)$ da amostra utilizando um procedimento estatístico específico denominado "Peaks over Threshold method"(POT) - Método dos excedentes além de um limiar -, desenvolvido com o uso da Teoria dos Valores Extremos - TVE. A utilização desse procedimento é justificada pela necessidade de se reconstituir a cauda direita de $F_{Z_{p}}$. Entre os métodos estatísticos paramétricos aplicáveis ao caso em questão, o método POT é preferível por duas razões: primeiro por ser usado frequentemente com sucesso nos estudos contemporâneos de dados financeiros; segundo, por ser intimamente relacionado a um particular procedimento que é utilizado no segundo método que foi usado para estimar $\operatorname{Var}_{\alpha}\left(Z_{p}\right)$. Esse método POT é exposto em detalhes no paper em questão.

- o $2^{\text {o }}$ método é o sugerido recentemente por Longin(2000). Para apresentá-lo são necessárias algumas noções de variáveis aleatórias da TVE. No paper é descrito da seguinte forma:

Considerando as variáveis aleatórias $X$ e $Y$, seja então $\left(X_{i}, Y_{i}\right), i \in N$ sequência de cópias independentes de $(X, Y)$. Introduz-se:

$M_{m}:=\max X_{1}, \ldots, X_{m}$, e $L_{m}:=\max Y_{1}, \ldots, Y_{m}$ para todo $m \in N$

Então, o Teorema Central da TVE (veja Teorema 1.4.2 na página 11 de Leadbetter et al (1983)) garante que existem sequências numéricas apropriadas $a_{m}, b_{m}, a_{m}^{\prime}$ e $b_{m}^{\text {, }}$ de tal 
forma que:

$M:=\lim _{m \rightarrow \infty}\left(a_{m}\left(M_{m}-b_{m}\right)\right)$, e $L:=\lim _{m \rightarrow \infty}\left(a_{m}^{\prime}\left(L_{m}-b_{m}^{\prime}\right)\right)$

são duas variáveis aleatórias bem definidas. São chamadas variáveis aleatórias extremas correspondentes às funções de distribuições $F_{X}$ e $F_{Y^{\prime}}$, respectivamente. Seja:

$\rho(M, L)=\frac{E[(M-E(M))(L-E(L))]}{\sqrt{\operatorname{Var}(M) \cdot \operatorname{Var}(L)}}$

denotado por coeficiente de correlação linear entre as variáveis aleatórias extremas correspondentes a $F_{X}$ e $F_{Y}$.

Segundo a Propriedade (Longin 2000): Para $\alpha$ tendendo a 1 ou a 0 , sejam $\operatorname{Var}_{\alpha}(X), \operatorname{Var}_{\alpha}(Y)$ e $\rho(M, L)$ estimado por método apropriado da TVE. Então há evidências empíricas e indicações teóricas para o fato de que para todo $p \in(0,1)$, a expressão:

$\left.p \operatorname{Var}_{\alpha}(X)\right)^{2}+2 \rho(M, L) p(1-p) \operatorname{Var}_{\alpha}(X) \operatorname{Var}_{\alpha}(Y)+\left((1-p) \operatorname{Var}_{\alpha}(Y)\right)^{2}$

fornece a estimativa de $\left(\operatorname{Var}_{\alpha}\left(Z_{p}\right)\right)^{2}$ a qual é mais precisa e confiável de que estimativas fornecidas por métodos tradicionais.

Da comparação desses dois métodos, surge o coeficiente implícito de dependência extremal, sugerido pelo seguinte procedimento:

- (a) obter a estimativa de $\operatorname{Var}_{\alpha}\left(Z_{p}\right)$ aplicando o método POT;

- (b) obter as estimativas de $\left.\operatorname{Var}_{(} X\right)$ e $\left.\operatorname{Var}_{(} Y\right)$ aplicando o método POT;

- (c) substituir os valores de $\left.\operatorname{Var}_{(} X\right)$ e $\left.\operatorname{Var}_{(} Y\right)$ obtidos no item anterior na expressão:

$\left.\left(\operatorname{Var}_{\alpha}\left(Z_{p}\right)\right)^{2}=p \operatorname{Var}_{\alpha}(X)\right)^{2}+2 \rho(M, L) p(1-p) \operatorname{Var}_{\alpha}(X) \operatorname{Var}_{\alpha}(Y)+\left((1-p) \operatorname{Var}_{\alpha}(Y)\right)^{2}$ para encontrar o valor de $\rho(M, L)$.

É claro que a sugestão é encontrar o valor do coeficiente implícito $\rho(M, L)$ por meio da expressão acima. A imperfeição da sugestão está que, se por um lado, $\rho(M, L)$ não depende de $p$, por outro lado, o procedimento descrito acima seria uma função de $p$. Nesse sentido, a sugestão oferecida no paper é a modificação do item (c) de tal forma que o valor de $\rho(M, L)$ seria independente de $p$ pela definição:

- (c') encontrar o valor de $\varrho$ que minimiza o valor da expressão:

$\sum_{G}\left\{\left[\left(p \hat{\operatorname{Var}}{ }_{\alpha}(X)\right)^{2}+2 \varrho p(1-p) \hat{\operatorname{Var}}{ }_{\alpha}(X) \hat{\operatorname{Var}} \alpha(Y)+((1-p) \hat{\operatorname{Var}}(Y))^{2}\right]^{1 / 2}-\left[\hat{\operatorname{Var}}\left(Z_{p}\right)\right]\right\}^{2}$

onde $G=0.01,0.02, \ldots, 0.99$.

Os autores do paper consideram que quando $\alpha$ tende a 1 , o valor de $\varrho$, estabelecido pela 
implementação dos itens (a), (b) e (c') mediria a dependência entre valores extremamente grandes de $X$ e $Y$. Assim, esse é o coeficiente de dependência extremal a nível $\alpha$ entre as variáveis $X$ e $Y$, denotado por $\varrho_{X<Y}(\alpha)$. Ainda, nesse paper é exibida uma secção em que são deduzidas propriedades do coeficiente que certamente o justificam poder ser considerado como medida de dependência entre variáveis aleatórias.

\subsection{Procedimento Experimental}

Para a realização deste ensaio, a $1^{\circ}$ etapa foi a construção das séries de retornos bivariadas dos ativos em estudo, correspondentes a níveis de estimativas de volatilidade. Optamos por uma escolha empírica, de tal forma que as séries assim obtidas pudessem ser representativas da amostra total e possibilitassem a nossa análise quanto ao comportamento dos pares de retornos de ativos conforme suas estimativas de volatilidade fossem mais altas de que determinados níveis. A Tabela 6.1 exibe o procedimento adotado para a obtenção dos níveis de estimativas de volatilidade formando, dessa forma, as faixas para os pares de ativos. Esclarecemos que em alguns casos o número de faixas teve que ser reduzido pelo fato de que as séries obtidas não apresentavam número de observações passíveis de análise.

Tabela 6.1: Critério adotado para obtenção das séries bivariadas de retornos dos ativos de acordo com o nível comum de estimativas de volatilidade

\begin{tabular}{|l|l|}
\hline Faixas & Critério adotado \\
\hline \hline Faixa 1 & Retornos dos ativos 1 e 2 \\
\hline Faixa 2 & Ret. correspondentes a estimativas de $V . E .>\mu($ média $)-0.5 d . p$. do Ativo 1 \\
\hline Faixa 3 & Ret. correspondentes a estimativas de $V . E .>\mu($ média $)$ do Ativo 1 \\
\hline Faixa 4 & Ret. correspondentes a estimativas de $V . E .>\mu($ média $)+0.5 d . p$. do Ativo 1 \\
\hline Faixa 5 & Ret. correspondentes a estimativas de $V . E .>\mu($ média $)-0.5 d . p$. do Ativo 2 \\
\hline Faixa 6 & Ret. correspondentes a estimativas de $V . E .>\mu($ média $)$ do Ativo 2 \\
\hline Faixa 7 & Ret. correspondentes a estimativas de $V . E .>\mu($ média $)+0.5 d . p$. do Ativo 2 \\
\hline \hline
\end{tabular}

Nota 1: As faixas, p/ apresentação, foram reordenadas pelo nível de volat. crescente.

Para obtermos a dependência dos retornos nos dois casos: por faixas, ou seja, o comportamento da dependência conforme mudamos a faixa, e o comportamento da dependência dos retornos simultâneos em cada faixa relativamente a períodos em que crises ou euforia dos mercados financeiros são mais acentuadas, utilizamos o coeficiente implícito exibido na Seção 6.1, denominado por $\varrho$ neste trabalho também. Essa medida de dependência permite aproximar quantis elevados de distribuição bivariada pela combinação dos quantis das distribuições marginais. Analisamos o comportamento do coeficiente de dependência extremal em duas situações:

- posições longas nos dois ativos: risco de quedas conjuntas retratado por $\varrho^{B B}$ 
- posições curtas nos dois ativos: risco de altas conjuntas retratado por $\varrho^{A A}$

No primeiro caso deste ensaio, optamos pelo quantil $\alpha=0.95$ e estimamos $\varrho^{A A}$ e $\varrho^{B B}$ (este a partir da amostra com sinais invertidos) para cada par de ativos e verificamos como a medida de dependência evolui conforme mudamos de faixa. Para exemplificar: considerando um par dc ativos, cntão $\varrho^{B B}$ para $\alpha=0.95$ expressa a dependência estimada entre os $5 \%$ menores retornos (perdas) de cada um dos ativos e, $\varrho^{A A}$ para $\alpha=0.95$ expressa a dependência estimada dos retornos que, em cada ativo, são superiores a $95 \%$ das demais estimativas dos retornos daqueles mesmos ativos.

No segundo caso deste ensaio, verificamos como $\varrho^{A A}$ e $\varrho^{B B}$ (este invertendo o sinal da amostra) varia em relação a quantis tendendo ao extremo da cauda direita da função de distribuição acumulada. Foram escolhidos arbitrariamente valores de $\alpha=0.95, \alpha=0.96$, $\alpha=0.97, \alpha=0.98, \alpha=0.99, \alpha=0.995$ e $\alpha=0.999$.

Nos dois casos, o procedimento experimental foi realizado com a aplicação de programa em Stat Pascal que é compilado no software Extremes. Esse programa, gerou 50 estimativas aleatórias de $k$ estatísticas de ordem - número de extremos que compõem a cauda da distribuição - para valores entre $5 \%$ e $15 \%$ do tamanho da amostra. Assim, utilizando as 50 estimativas de $k$ calculou 50 estimativas de $\varrho$ em cada estudo analisado. Dessa forma, apresentamos os resultados obtidos em tabelas e gráficos do tipo boxplot de ( $\varrho$, Faixas $)$ no primeiro caso e do tipo boxplot $(\varrho, \alpha)$ no segundo caso. 


\subsection{Resultados}

\subsection{1 $1^{\circ}$ Caso - Análise da dependência de pares de ativos na mudança de faixas.}

Os resultados da $1^{\mathrm{a}}$ parte deste ensaio estão exibidos nas Figuras 6.1 a 6.15 . Dentre essas, esclarecemos que as de 6.3 a 6.9 foram incluídas apenas para exemplificação, por meio de scatterplot, das séries obtidas, por construção, do par Taxa Pré x Ibovespa. A Tabela 6.2 apresenta os resultados para $k-\mathrm{n}^{\circ}$ de estatísticas de ordem fixo ( 0.1 da amostra) e a Tabela 6.3 resume os resultados consistentes obtidos do procedimento quanto ao comportamento da dependência dos retornos dos ativos com as mudanças das faixas, isto é, dos retornos correspondentes a estimativas de volatilidade crescentes conjuntas, por meio da tendência das estimativas do coeficiente implícito de dependência extremal para as duas caudas e do coeficiente de correlação de cada série.

Tabela 6.2: Coeficiente implícito de dependência extremal por faixas. Utilização do método de máxima verossimilhança para aproximação por GPD para $k=0.1 \mathrm{~N}$

\begin{tabular}{|l|l|l|l|l|l|l|l|l|}
\hline \multicolumn{1}{|c|}{ Valores dos coeficientes com consistência para o Quantil=0.95 } \\
\hline \hline Par de ativos & Posição & FX 1 & FX 2 & FX 3 & FX 4 & FX 5 & FX 6 & FX 7 \\
\hline \hline \multirow{3}{*}{ TxPre x Ibovespa } & AA & -0.51 & -0.54 & -0.60 & -0.63 & - & - & - \\
\cline { 2 - 10 } & BB & -0.50 & -0.53 & -0.59 & -0.64 & - & - & - \\
\hline \hline \multirow{3}{*}{ TxPre x Dólar } & AA & 0.50 & 0.53 & 0.50 & 0.31 & - & - & - \\
\cline { 2 - 10 } & BB & 0.37 & 0.35 & 0.34 & 0.72 & - & - & - \\
\hline \hline \multirow{2}{*}{ TxPre x TxCupom } & AA & -0.15 & -0.20 & -0.19 & - & - & - & - \\
\cline { 2 - 9 } & BB & -0.16 & -0.26 & -0.34 & - & - & - & - \\
\hline \hline \multirow{2}{*}{ TxCupom x Dólar } & AA & -0.15 & -0.15 & -0.15 & -0.16 & - & - & - \\
\cline { 2 - 9 } & BB & -0.15 & -0.20 & -0.23 & - & - & - & - \\
\hline \hline
\end{tabular}


Tabela 6.3: Dependência dos pares de ativos conforme as mudanças de faixas

\begin{tabular}{|c|c|c|c|c|}
\hline Par de Ativos & Faixas & Coef. Correlação & Posição & Tendência de $\varrho$ \\
\hline \multirow[t]{8}{*}{ TxPre x Ibovespa } & FX 1 & - 0.59 & \multirow[t]{4}{*}{$\overline{\mathrm{AA}}$} & \multirow[t]{4}{*}{ Alta anti-correl. } \\
\hline & FX 2 & -0.59 & & \\
\hline & FX 3 & -0.61 & & \\
\hline & FX 4 & -0.64 & & \\
\hline & FX 1 & & \multirow[t]{4}{*}{$\mathrm{BB}$} & \multirow[t]{4}{*}{ Alta anti-correl. } \\
\hline & FX 2 & & & \\
\hline & FX 3 & & & \\
\hline & FX 4 & & & \\
\hline \multirow[t]{8}{*}{ TxPre x Dólar } & FX 1 & 0.28 & \multirow[t]{4}{*}{ AA } & \multirow[t]{4}{*}{ Queda } \\
\hline & FX 2 & 0.32 & & \\
\hline & FX 3 & 0.32 & & \\
\hline & FX 4 & 0.29 & & \\
\hline & FX 1 & & \multirow[t]{4}{*}{$\mathrm{BB}$} & \multirow[t]{4}{*}{ Alta } \\
\hline & FX 2 & & & \\
\hline & FX 3 & & & \\
\hline & FX 4 & & & \\
\hline \multirow[t]{6}{*}{ TxPre x TxCupom } & $\overline{\text { FX } 1}$ & - -0.14 & \multirow[t]{3}{*}{$\overline{\mathrm{AA}}$} & \multirow[t]{3}{*}{-} \\
\hline & FX 2 & -0.21 & & \\
\hline & FX 3 & -0.26 & & \\
\hline & FX 1 & & \multirow[t]{3}{*}{$\overline{\mathrm{BB}}$} & \multirow[t]{3}{*}{ Alta anti-correl. } \\
\hline & FX 2 & & & \\
\hline & FX 3 & & & \\
\hline \multirow[t]{7}{*}{ TxCupom x Dólar } & FX 1 & -0.15 & \multirow[t]{4}{*}{$\overline{\mathrm{AA}}$} & \multirow[t]{4}{*}{ Estabilidade } \\
\hline & FX 2 & -0.15 & & \\
\hline & FX 3 & -0.16 & & \\
\hline & FX 4 & -0.19 & & \\
\hline & FX 1 & & \multirow[t]{3}{*}{$\mathrm{BB}$} & \multirow[t]{3}{*}{ Alta anti-correl. } \\
\hline & FX 2 & & & \\
\hline & Fx 3 & & & \\
\hline
\end{tabular}


Par: Taxa Pré x Ibovespa

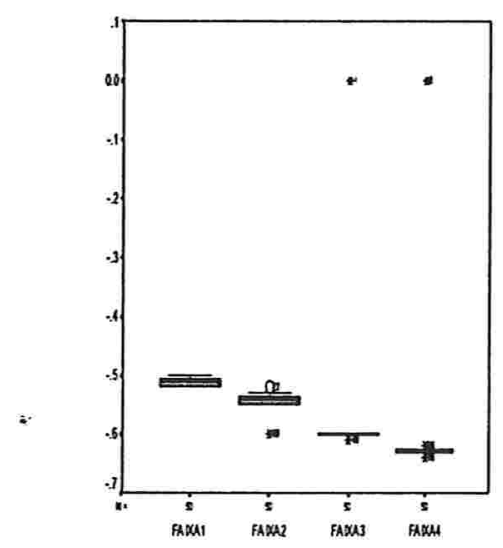

Figura 6.1: Evolução do coeficiente de dependência extremal - Posição AA

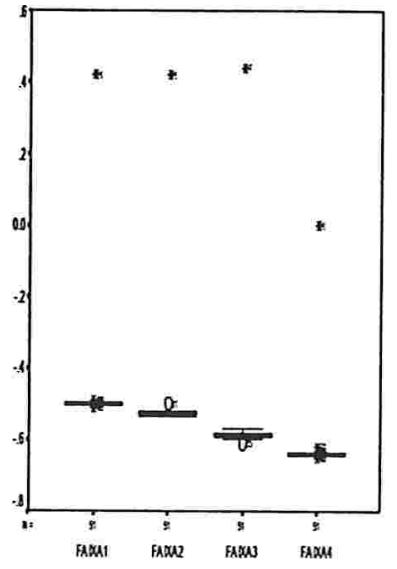

Figura 6.2: Evolução do coeficiente de dependência extremal - Posição $\mathrm{BB}$ 


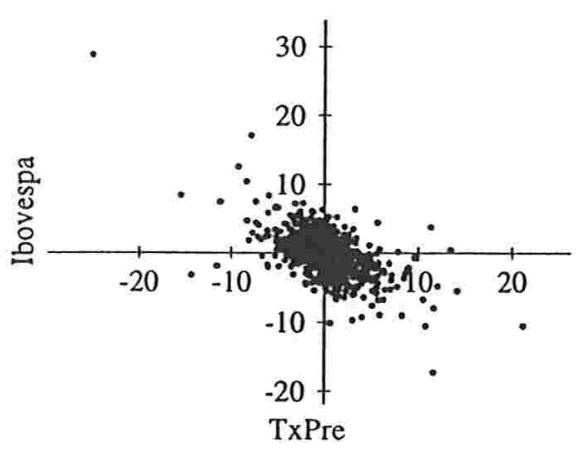

Figura 6.3: Scatterplot dos retornos - Faixa 1

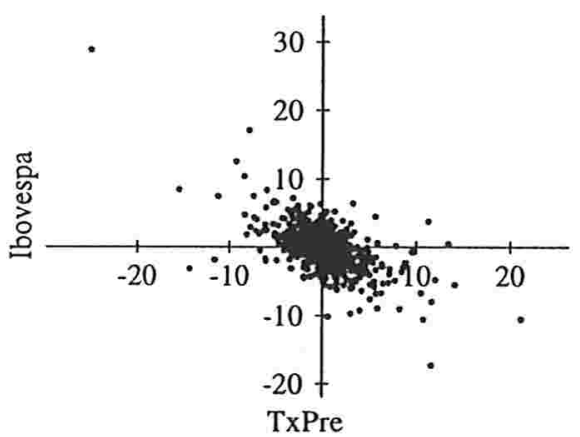

Figura 6.5: Scatterplot dos retornos - Faixa 3

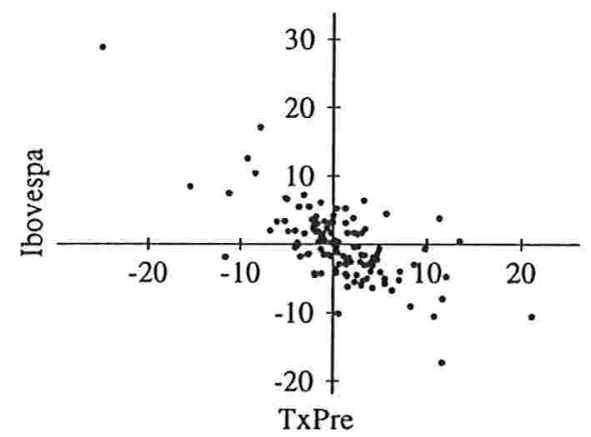

Figura 6.7: Scatterplot dos retornos - Faixa 5

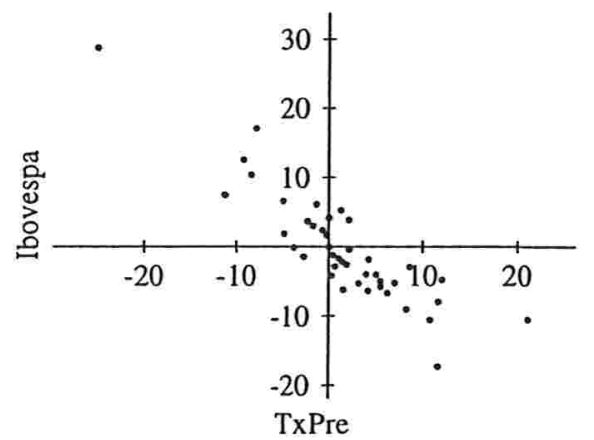

Figura 6.9: Scatterplot dos retornos - Faixa 7

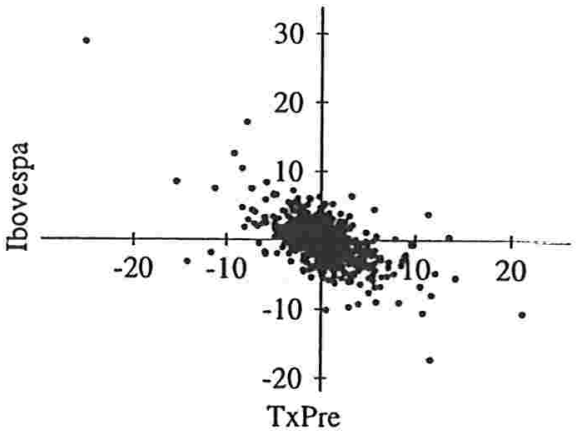

Figura 6.4: Scatterplot dos retornos - Faixa 2

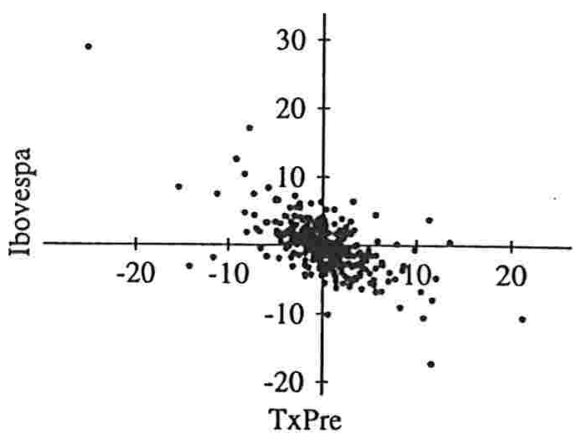

Figura 6.6: Scatterplot dos retornos - Faixa 4

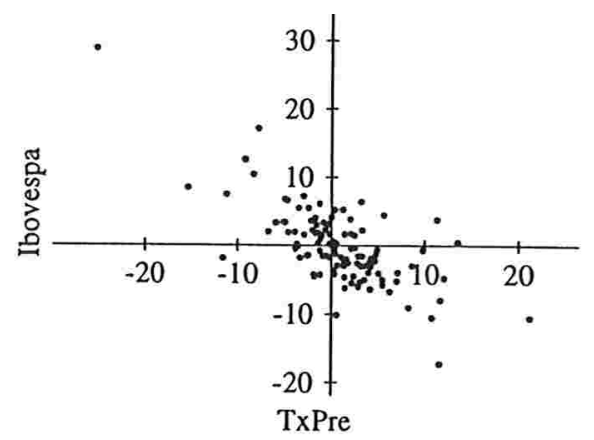

Figura 6.8: Scatterplot dos retornos - Faixa 6 


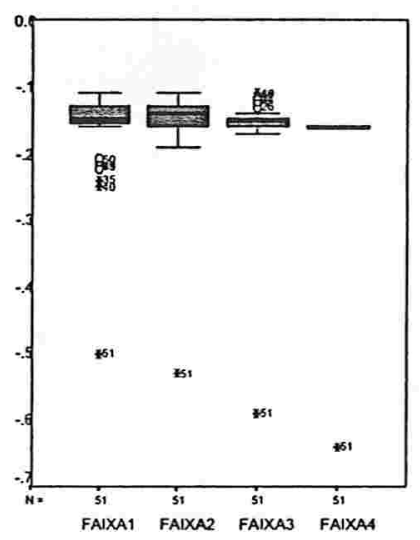

Figura 6.10: Evolução do coeficiente de dependência extremal Posição AA

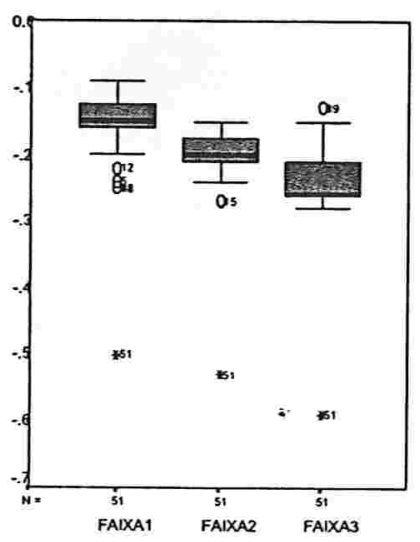

Figura 6.11: Evolução do coeficiente de dependência extremal Posição BB 
Par: Taxa Pré x Dólar
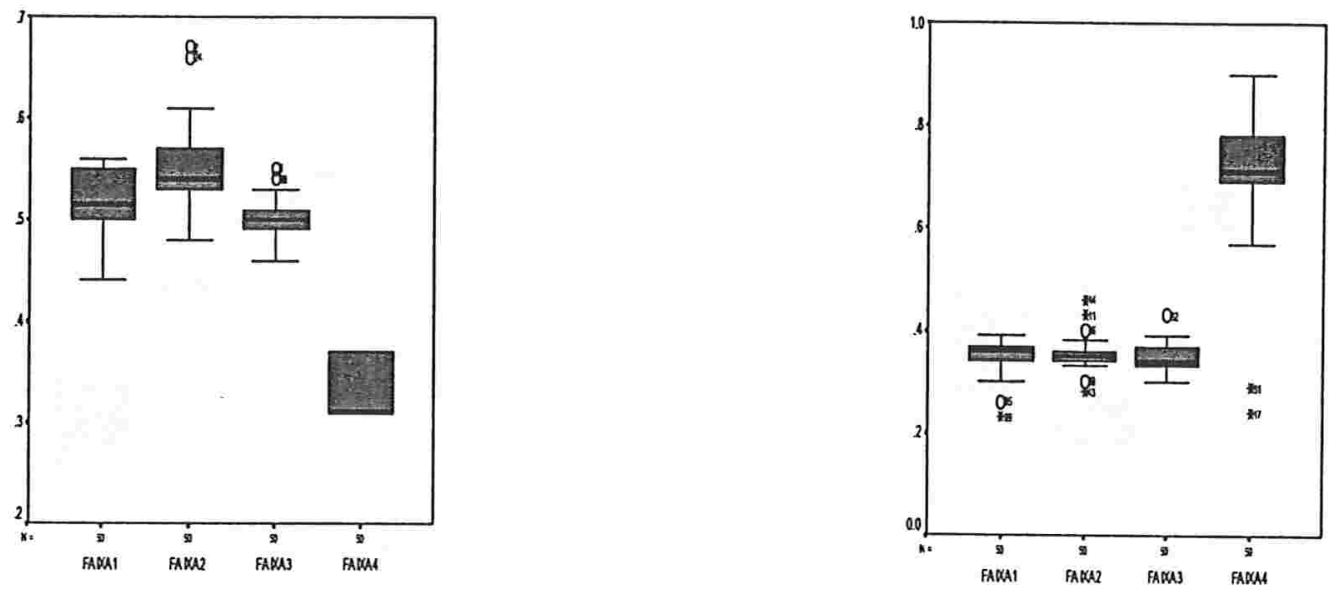

Figura 6.12: Evolução do coeficiente de dependência extremal Posição AA

Figura 6.13: Evolução do coeficiente de dependência extremal Posição BB 
Par: Taxa Pré x Taxa Cupom

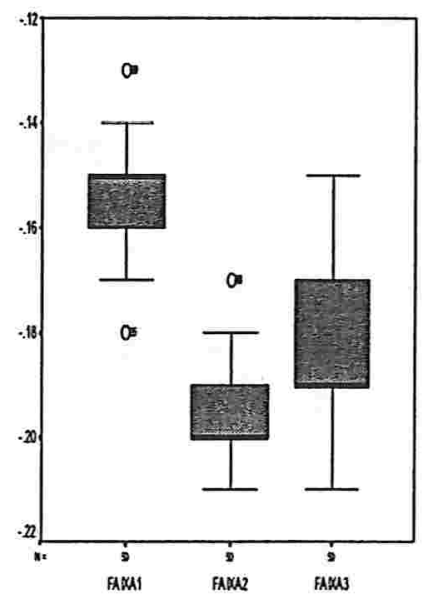

Figura 6.14: Evolução do coeficiente de dependência extremal Posição AA

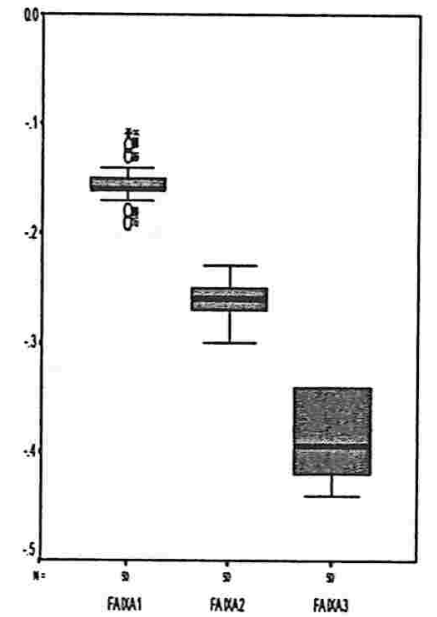

Figura 6.15: Evolução do coeficiente de dependência extremal Posição BB 


\subsection{2 $2^{\circ}$ Caso - Análise da dependência extremal de pares de ativos em cada faixa.}

Os resultados da $2^{\mathrm{a}}$ parte deste ensaio estão exibidos nas Figuras 6.16 a 6.31. A Tabela 6.4 resume os resultados consistentes obtidos do procedimento quanto ao comportamento da dependência extremal dos retornos dos ativos em cada faixa, por meio da tendência das estimativas do coeficiente implícito de dependência extremal $(\varrho)$ para as duas caudas.

Tabela 6.4: Dependência extremal dos pares de ativos em cada faixa

\begin{tabular}{|c|c|c|c|}
\hline Par de Ativos & Posição & Faixas & Tendência de $\varrho$ \\
\hline \multirow[t]{8}{*}{ TxPre x Ibovespa } & \multirow{4}{*}{ AA } & FX 1 & Alta anti-correl. \\
\hline & & FX 2 & Estabilidade \\
\hline & & FX 3 & Estabilidade \\
\hline & & FX 4 & Estabilidade \\
\hline & \multirow[t]{4}{*}{$\mathrm{BB}$} & FX 1 & Alta anti-correl. \\
\hline & & FX 2 & Alta anti-correl. \\
\hline & & FX 3 & Alta anti-correl. \\
\hline & & FX 4 & Estabilidade \\
\hline \multirow[t]{8}{*}{ TxPre x Dólar } & \multirow[t]{4}{*}{$\mathrm{AA}$} & FX 1 & Queda \\
\hline & & FX 2 & Queda \\
\hline & & FX 3 & Queda \\
\hline & & FX 4 & Queda \\
\hline & \multirow[t]{4}{*}{$\mathrm{BB}$} & FX 1 & Queda \\
\hline & & FX 2 & - \\
\hline & & FX 3 & - \\
\hline & & FX 4 & Queda \\
\hline
\end{tabular}




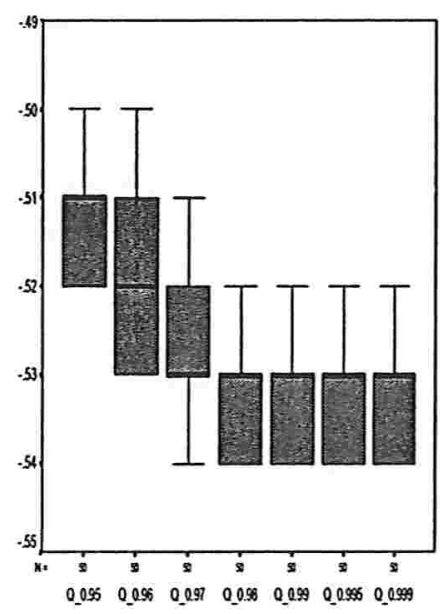

Figura 6.16: Par: Taxa Pré x Ibovespa. Evolução de $\varrho^{A A}-$ Dependência nos extremos superiores - Faixa 1

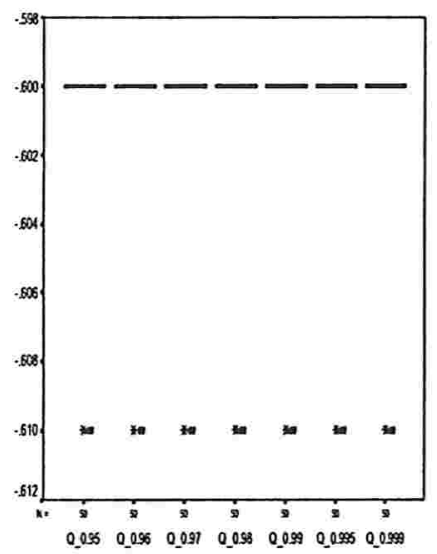

Figura 6.18: Par: Taxa Pré x Ibovespa. Evolução de $\varrho^{A A}-$ Dependência nos extremos superiores - Faixa 3

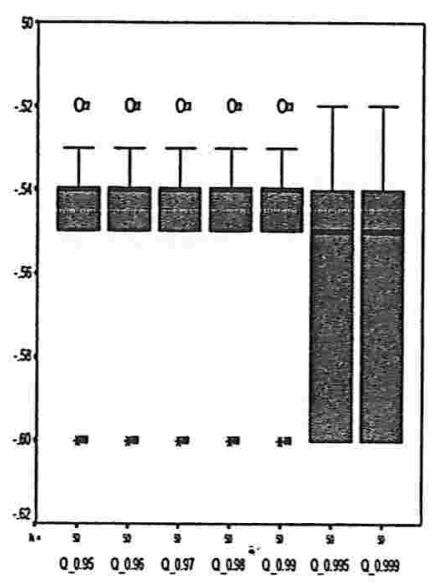

Figura 6.17: Par: Taxa Pré $\mathrm{x}$ Ibovespa. Evolução de $\varrho^{A A}-$ Dependência nos extremos superiores - Faixa 2

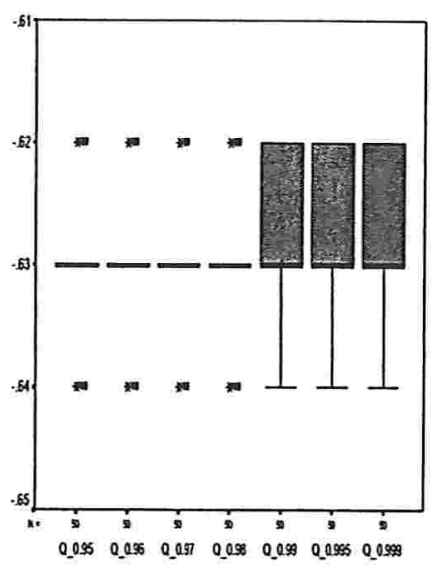

Figura 6.19: Par: Taxa Pré x Ibovespa. Evolução de $\varrho^{A A}-\mathrm{De}$ pendência nos extremos superiores - Faixa 4 


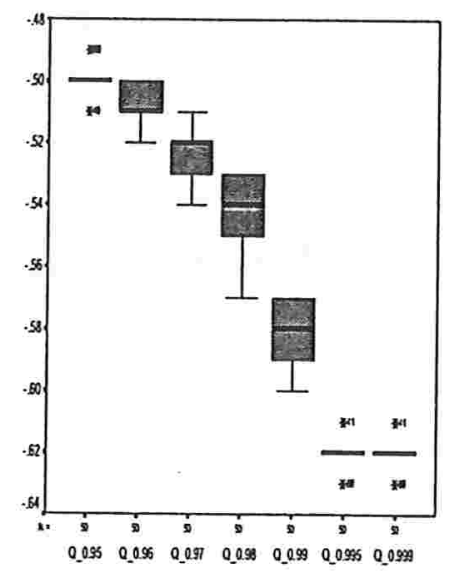

Figura 6.20: Par: Taxa Pré $\mathrm{x}$ Ibovespa. Evolução de $\varrho^{B B}-$ Dependência nos extremos inferiores Faixa 1

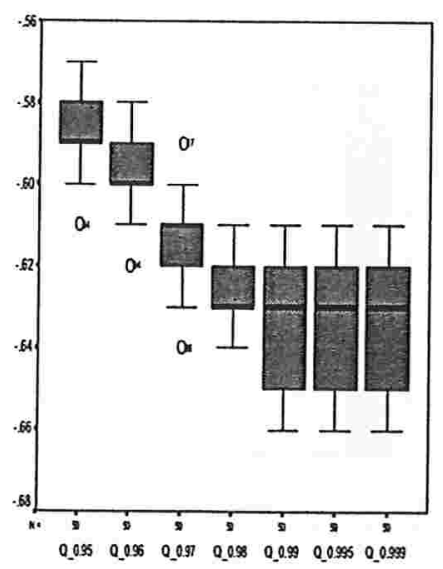

Figura 6.22: Par: Taxa Pré $\mathrm{x}$ Ibovespa. Evolução de $\varrho^{B B}-$ Dependência nos extremos inferiores Faixa 3

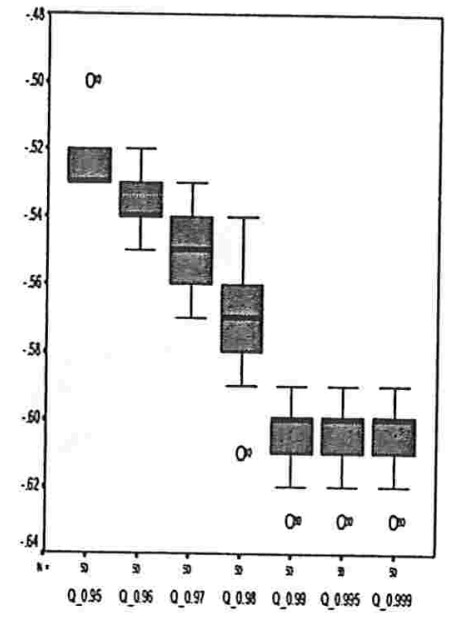

Figura 6.21: Par: Taxa Pré x Ibovespa. Evolução de $\varrho^{B B}$ - Dependência nos extremos inferiores Faixa 2

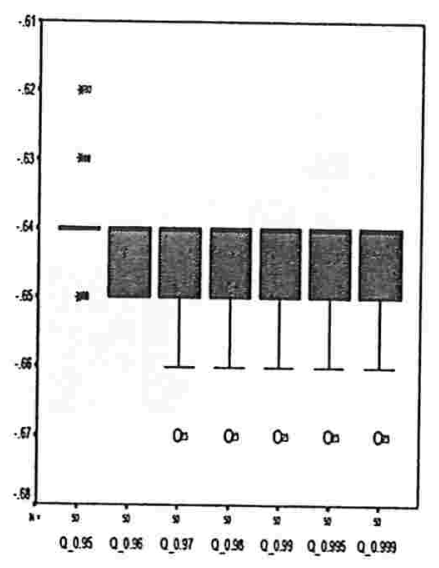

Figura 6.23: Par: Taxa Pré $\mathrm{x}$ Ibovespa. Evolução de $\varrho^{B B}-$ Dependência nos extremos inferiores Faixa 4 


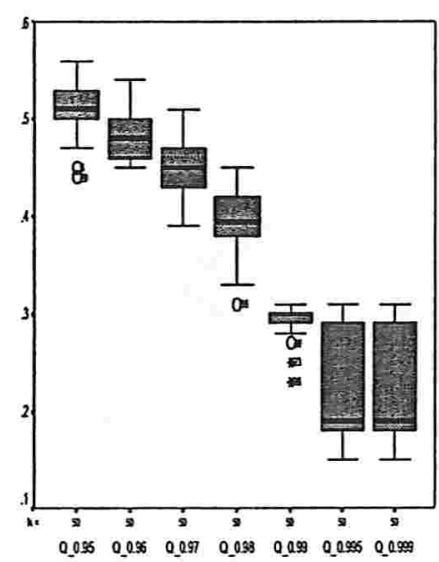

Figura 6.24: Par: Taxa Pré x Dólar. Evolução de $\varrho^{A A}$ - Dependência nos extremos superiores - Faixa 1

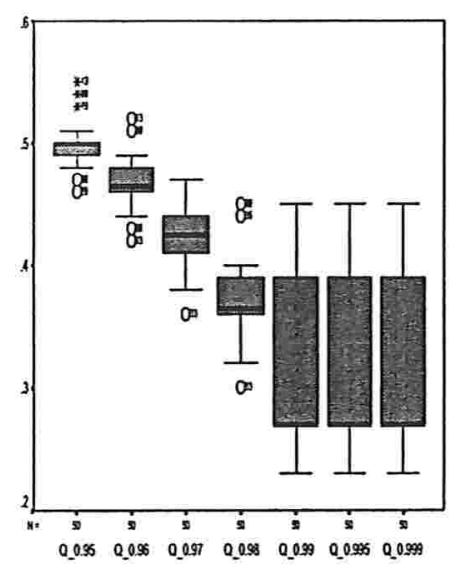

Figura 6.26: Par: Taxa Pré $\mathrm{x}$ Dólar. Evolução de $\varrho^{A A}$ - Dependência nos extremos superiores - Faixa 3

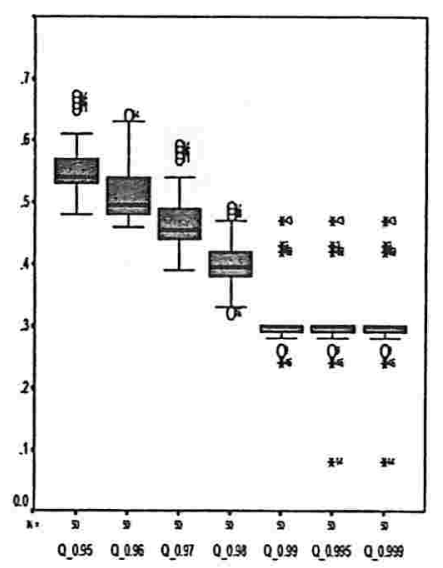

Figura 6.25: Par: Taxa Pré x Dólar. Evolução de $\varrho^{A A}$ - Dependência nos extremos superiores - Faixa 2

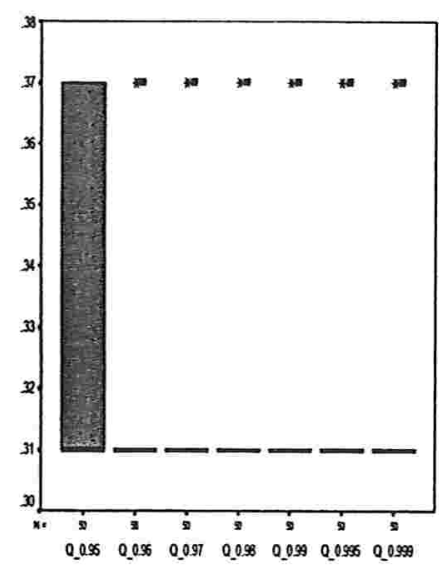

Figura 6.27: Par: Taxa Pré x Dólar. Evolução de $\varrho^{A A}$ - Dependência nos extremos superiores - Faixa 4 


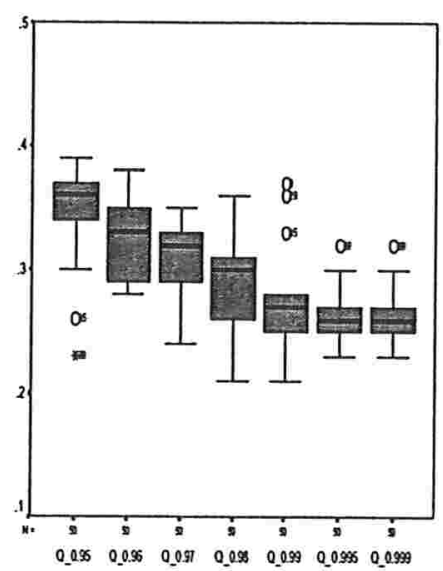

Figura 6.28: Par: Taxa Pré x Dólar. Evolução de $\varrho^{B B}$ - Dependência nos extremos inferiores - Faixa 1

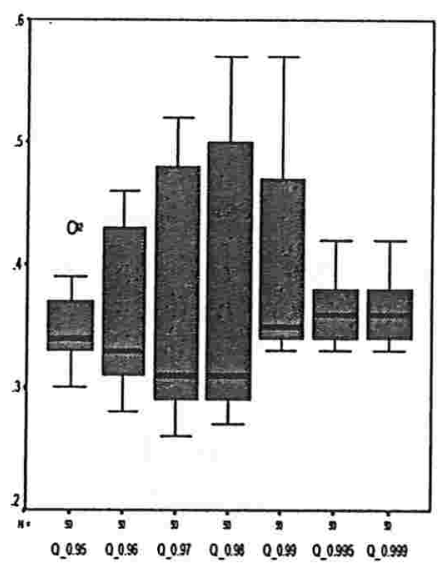

Figura 6.30: Par: Taxa Pré x Dólar. Evolução de $\varrho^{B B}$ - Dependência nos extremos inferiores - Faixa 3

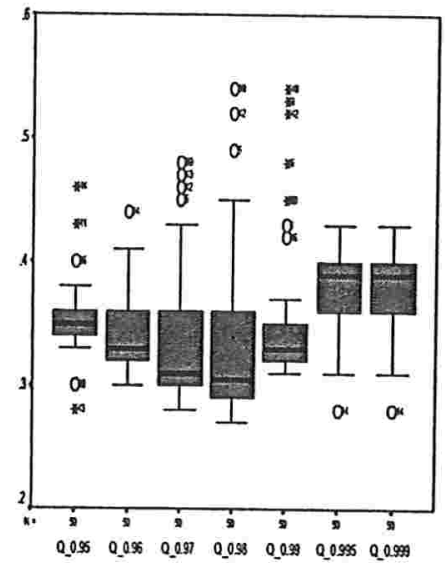

Figura 6.29: Par: Taxa Pré x Dólar. Evolução de $\varrho^{B B}$ - Dependência nos extremos inferiores - Faixa 2

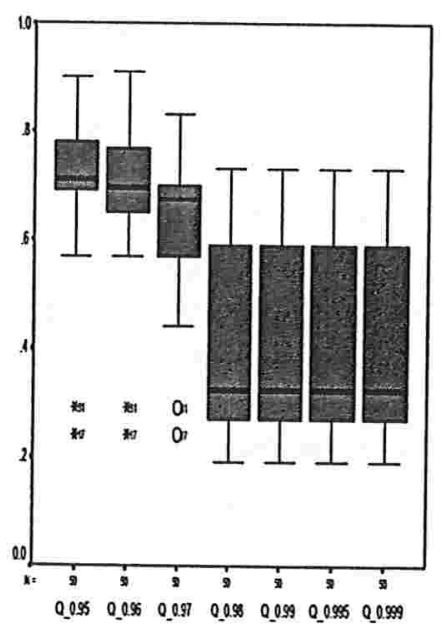

Figura 6.31: Par: Taxa Pré x Dólar. Evolução de $\varrho^{B B}$ - Dependência nos extremos inferiores - Faixa 4 


\subsection{Conclusão}

Para os dois casos deste Ensaio, apresentamos a interpretação dos resultados exibidos na Secção anterior para cada par analisado.

* $1^{\circ}$ Caso

- Par: Taxa Pré x Ibovespa -

O comportamento é semelhante nas duas caudas, indicando anti-correlação mais alta entre os retornos correspondentes a estimativas de volatilidade mais altas.

\section{- Par: Taxa Pré x Dólar -}

As caudas têm comportamento distintos; a cauda direita indica queda na dependência conforme muda-se de faixas de retornos correspondentes a estimativas de volatilidade mais altas, enquanto que a cauda esquerda indica que, embora haja fraca dependência, nas faixas iniciais os coeficientes de dependência mostram estabilidade e, na faixa mais alta com resultados consistentes, a dependência é mais alta.

\section{- Par: Taxa Pré x Taxa Cupom -}

As caudas possuem comportamento diferenciados; na cauda direita, a análise dos valores de coeficiente de dependência não se mostrou conclusiva relativamente à mudança de faixas, enquanto que na cauda esquerda, há acentuado aumento na anti-correlação.

- Par: Taxa Cupom x Dólar -

O comportamento é diferenciado nas duas caudas; a cauda direita indica, embora pequena, anti-correlação entre os retornos no mesmo nível em todas as faixas, enquanto que na cauda esquerda há uma leve tendência de aumento na anti-correlação conforme as mudanças de faixas.

Obs.: Os resultados do coeficiente de correlação das séries, exibidos na Tabela 6.3 na Seç̧ão Resultados, não permitiria distinguir o comportamento diferenciado de dependência das duas caudas, embora seus valores estivessem indicando situações de correlação e anticorrelação dos pares convenientemente.

* $2^{\circ}$ Caso

- Par: Taxa Pré x Ibovespa -

As duas caudas apresentam indicação de anti-correlação, sendo que, na cauda direita, a faixa 1 indica alta na anti-correlação para valores mais extremos (situações de eufo- 
ria) e, as demais faixas indicam estabilidade do coeficiente de dependência para todos os níveis de $\alpha$. Já na cauda esquerda somente na faixa 4 há indicativo de estabilidade do coeficiente para todos os valores de $\alpha$, enquanto que nas demais há indicativo de alta na anti-correlação para valores mais extremos de retornos (situações de crise)

- Par: Taxa Pré x Dólar -

Nas duas caudas há indicativo de dependência fraca, sendo que na cauda direita a dependência diminui para valores mais extremos na análise de todas as faixas, enquanto que na cauda esquerda as faixas 1 e 4 indicam queda na dependência para valores mais extremos e, nas faixas 2 e 3 a análise não pode ser conclusiva no tocante à dependência. 


\section{Referências Bibliográficas}

John C. Hull. Opções, Futuros e Outros Derivativos, 1997.

Philippe Jorion. Value at Risk, 1999.

Pedro A. Morettin e Clélia M. C. Toloi. Análise de Séries Temporais, 2004.

Peter J. Brockwell e Richard A. Davis. Introduction to time Serie and Forecasting, 2002.

Motta A.C.O. Modelos de Espaço de Estados Não-Gaussianos e o Modelo de Volatilidade Estocástica. Dissertação de Mestrado. IMECC-UNICAMP.

S. J. Koopman, A. Harvey, J. Doornik e N. Shephard. STAMP book, 1998.

P. Embrechts, C. Kluppelberg e T. Mikosch. Modelling Extremal Events for Insurance and Finance, 1997.

R.D. Reiss e M. Thomas. Statistical Analysis of Extreme Values, 2001.

A. Panzieri, V. Belitsky, P.M. Rocha e F. P. Almeida Prado. Identification of change in asset's dependence in market booms and crises via implicit coefficient of extreme dependence. Working paper, 2004.

B. Boyer, M. Gibson e M. Loretan. Pitfalls un tests for changes in correlations, 2001. 